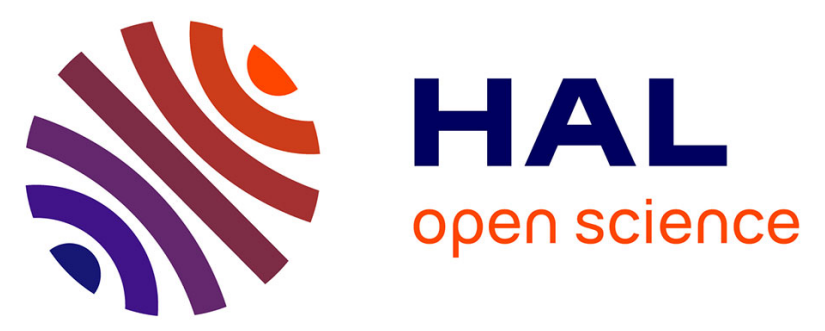

\title{
Une occupation de la phase ancienne du Paléolithique moyen à Therdonne (Oise) : chronostratigraphie, production de pointes Levallois et réduction des nucléus
}

Jean-luc Locht, Pierre Antoine, David Hérisson, Guillaume Gadebois, Nick Debenham

\section{To cite this version:}

Jean-luc Locht, Pierre Antoine, David Hérisson, Guillaume Gadebois, Nick Debenham. Une occupation de la phase ancienne du Paléolithique moyen à Therdonne (Oise) : chronostratigraphie, production de pointes Levallois et réduction des nucléus. Gallia Préhistoire - Préhistoire de la France dans son contexte européen, 2010, 52, pp.1-32. hal-01385273

\section{HAL Id: hal-01385273 \\ https://hal.science/hal-01385273}

Submitted on 21 Oct 2016

HAL is a multi-disciplinary open access archive for the deposit and dissemination of scientific research documents, whether they are published or not. The documents may come from teaching and research institutions in France or abroad, or from public or private research centers.
L'archive ouverte pluridisciplinaire $\mathbf{H A L}$, est destinée au dépôt et à la diffusion de documents scientifiques de niveau recherche, publiés ou non, émanant des établissements d'enseignement et de recherche français ou étrangers, des laboratoires publics ou privés.

\section{(1) (1) $\$$}

Distributed under a Creative Commons Attribution - NonCommercial - NoDerivatives $\mid 4.0$ 


\title{
UNE OCGUPATION DE LA PHASE ANCIENNE DU PALÉOLITHIQUE MOYEN À THERDONNE (OISE)
}

\section{Chronostratigraphie, production de pointes Levallois et réduction des nucléus}

\author{
Jean-Luc LOCHT ${ }^{1}$, Pierre ANTOINE ${ }^{2}$, David HÉRISSON ${ }^{3}$, Guillaume GADEBOIS ${ }^{4}$ \\ et Nick DEBENHAM ${ }^{5}$
}

\begin{abstract}
Mots-clés. Paléolithique moyen ancien, pointe Levallois, Saalien, nord de la France.
Résumé. À la fin du stade isotopique 7, vers 170-190 ka BP, les Préhistoriques sont venus sinstaller sur le pied de versant de la butte tertiaire du mont de Bourguillemont à Therdonne (Oise). Situé à moins de $4 \mathrm{~km}$ du gisement paléolithique moyen récent de la Justice à Beauvais (Oise), le site de Therdonne offre les mêmes avantages propices à l'installation de groupes paléolithiques. La fouille préventive du gisement a notamment livré un niveau archéologique N3, à l'état de conservation exceptionnel. Cet article a pour objectif de poser le cadre chronostratigraphique du gisement et de présenter les premiers résultats concernant l'étude du niveau archéologique N3, et plus particulièrement l'étude des pointes Levallois, un des principaux objectifs de production de l'occupation. Ce gisement s'intègre dans le cadre archéologique pauvre en découvertes de la phase ancienne du Paléolithique moyen, ce qui fait de l'occupation N3 un des rares témoignages, bien calé chronologiquement, attribuables au Saalien.
\end{abstract}

Key-words. Early Middle Paleolithic, Levallois point, Saalian, Northern France.

Abstract. At the end of Isotope Stage 7, approximately 170-190 ka BP, prehistoric hunter-gatherers occupied a site at the slope foot of the tertiary hill of Bourguillemont in Therdonne (Oise). The site of Therdonne, located less than $4 \mathrm{~km}$ from the Late Middle Paleolithic site of La Justice in Beauvais, presents the same advantages encouraging installation of Paleolithic groups. The preventive excavation of this site yielded an exceptionally well preserved archaeological level N3. The objective of this paper is to lay out the chronostratigraphic framework of this site and to present the first results of the study of archaeological level N3, with particular focus on the study of its Levallois points, one of the main objectives of the lithic production during this occupation. This site forms part of the Early Middle Paleolithic, which is an archaeological context poor in discoveries; the N3 occupation is thus one of the rare testimonies with a reliable chronological framework, attributable to the Saalian period.

Translation: Magen O'FARRELL

1. Inrap, 518 rue Saint-Fuscien, F-80 000 Amiens. Courriel: jean-luc.locht@inrap.fr

2. UMR 8591 du CNRS, Laboratoire de géographie physique, 1 place Aristide-Briand, F-92195 Meudon Cedex. Courriel: pierre-antoine@cnrsbellevue.fr

3. UMR 8164 du CNRS, UFR de Géographie, Université des sciences et technologies de Lille, avenue Paul-Langevin, F-59655 Villeneuve-d'Ascq Cedex. Courriel: davidherisson@yahoo.fr

4. UFR de géographie, Université des sciences et technologies de Lille, avenue Paul-Langevin, F-59655 Villeneuve-d'Ascq Cedex. Courriel: gadebois.g@ifrance.com

5. Quaternary TL Surveys, 19 Leonard Avenue, Nottingham NG5 2LW, United Kingdom. Courriel: n.debenham@qtls.globalnet.co.uk 


\section{LOCALISATION GÉOGRAPHIQUE ET HISTORIQUE DES TRAVAUX}

Le gisement paléolithique moyen de Therdonne se situe en Picardie, dans le département de l'Oise, à $5 \mathrm{~km}$ à l'est de la ville de Beauvais (fig. 1 , nos 1 et 2). Il fut découvert durant le printemps 1998 à l'occasion d'une campagne de sondages archéologiques sur le tracé de la déviation de la RN 31 à la hauteur du village de Laversines, faisant la liaison entre Beauvais et Clermont. Les coordonnées Lambert du site sont: $\mathrm{x}=588,200 ; \mathrm{y}=1190,790$ et altitude $=74 \mathrm{~m}$ NGF. Les occupations se trouvent en pied de versant, au nord-est d'une butte tertiaire résiduelle dénommée mont de Bourguillemont, surplombant d'environ $40 \mathrm{~m}$ le plateau (fig. 1, no 3 et fig. 2). Cette dernière est constituée de sables thanétiens (e2) surmontés des formations sparnaciennes (e3) et cuisiennes (e4). Le substrat crétacé est constitué par la craie à Bélemnitelles du Campanien (C6). $\mathrm{Au}$ nord-est se déroule un plateau tandis qu'à $750 \mathrm{~m}$ au sud, le Thérain, affluent de l'Oise, vient inciser le plateau et offre un accès direct à la vallée de l'Oise située au sud-est, à moins de $30 \mathrm{~km}$ en suivant le cours d'eau (fig. 1, no 2). D'un point de vue paléogéographique, l'occupation principale se trouvait en bordure d'un ancien vallon incisé par ruissellement dans le substrat tertiaire (fig. 3). Cette structure a permis le piégeage d'un enregistrement pédosédimentaire d'une puissance de plus de $4 \mathrm{~m}$, essentiellement dominé par les processus de versant (ruissellement, gélifluxion). Les sondages ont livré quatre niveaux archéologiques, nommés N1 à N4. Tenant compte des différents états de conservation des niveaux, l'objectif principal de l'opération d'août à novembre 1999 a été la fouille du niveau N3, très riche en artefacts lithiques et parfaitement conservé(fig. 4). Ce niveau a pu être fouillé à la main, relevé au $1 / 10$ et le sédiment tamisé sur $125 \mathrm{~m}^{2}$ (fig. 3). Cette méthode de fouille n'a pu être appliquée sur l'ensemble du gisement car il a été impossible de renégocier les moyens financiers de l'enveloppe fermée. Cette décision n'a pas été sans impact sur les résultats de l'opération. Ainsi, $147 \mathrm{~m}^{2}$ ont été fouillés à la main, le matériel a été récolté par quart de mètre carré et le sédiment ne fut pas tamisé. Enfin, 33 m² ont été explorés à la pelle mécanique avec prélèvement du matériel par quart de mètre carré et sédiment non tamisé. Au total, l'ensemble de la surface fouillée du niveau N3 s'étend sur $305 \mathrm{~m}^{2}$.

\section{CHOIX D'IMPLANTATION DES PRÉHISTORIQUES}

Le site du mont de Bourguillemont possédait plusieurs atouts attractifs pour les Préhistoriques. L'environnement immédiat devait proposer un accès rapide à l'eau avec le Thérain au sud, et de probables sources devaient exister sur les versants de la butte en raison de la présence d'argiles sparnaciennes imperméables (fig. $1, \mathrm{n}^{\circ} 3$ ). Le versant d'implantation, protégé par la butte tertiaire, formait un abri naturel face aux vents dominants d'ouest-nord-ouest. Le mont représentait aussi un point d'observation idéal offrant une vision panoramique sur plus de $10 \mathrm{~km}$ à la ronde. De plus, cette position topographique offrait un accès à un double biotope: le plateau dénudé au nord, où pouvaient être repérés d'éventuels troupeaux d'herbivores, et la vallée du Thérain qui offrait un accès à la vallée de l'Oise et par extension à celle de la Seine, permettant de faciliter les déplacements des Préhistoriques dans cette direction (fig. $1, n^{\circ} 2$ et fig. $2, n^{o s} 1,2$ ). Enfin, une matière première de qualité était disponible en grande quantité: silex de la craie campanienne, silex thanétien à cortex verdi et galets avellanaires des sables thanétiens (de mauvaise qualité). Situé à $5 \mathrm{~km}$ à l'ouest du site de Therdonne, le gisement de la Justice à Beauvais (aux alentours de $55,6 \pm 4 \mathrm{kaBP}$ ) avait déjà permis de mettre en évidence ces différents facteurs attractifs (fig. $1, \mathrm{n}^{\circ} 2$ ) : proximité de l'eau, abri des vents dominants au pied d'une butte tertiaire résiduelle, point d'observation panoramique, proximité des ressources alimentaires, matière première lithique de qualité et en quantité (Locht, 2001 et 2004).

\section{CADRE CHRONOSTRATIGRAPHIQUE DU GISEMENT}

La description des unités stratigraphiques du gisement est présentée dans le tableau I à la page 8 .

\section{ÉVOLUTION PÉDOSÉDIMENTAIRE SYNTHÉTIQUE ET INTERPRÉTATIONS GHRONOSTRATIGRAPHIQUES}

Sur la base de l'étude pédostratigraphique résumée dans le tableau I et de la morphostratigraphie synthétique (fig. 5), il est possible de mettre en évidence, dans les profils de Therdonne, une succession de deux cycles chronoclimatiques de type glaciaire-interglaciaire pouvant être résumés par la succession suivante. 


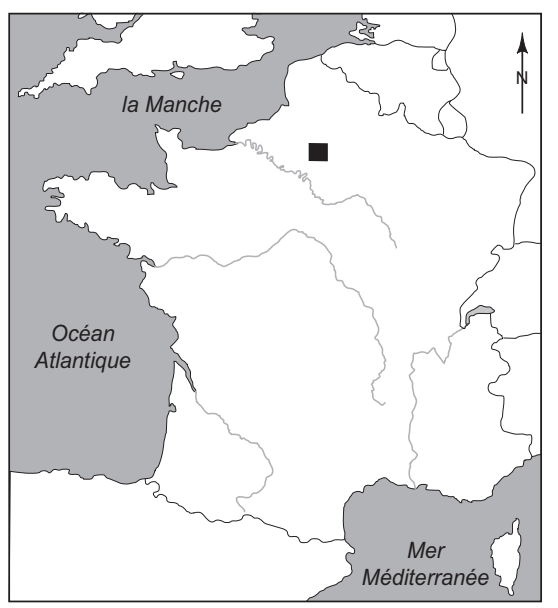

1

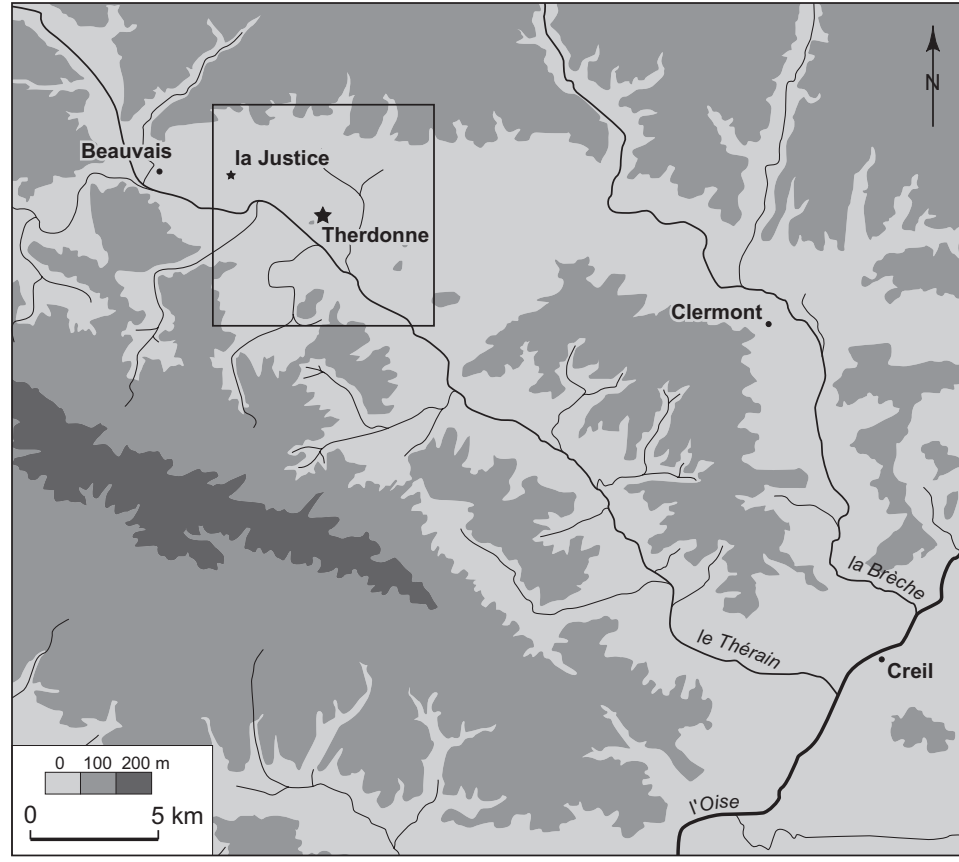

2

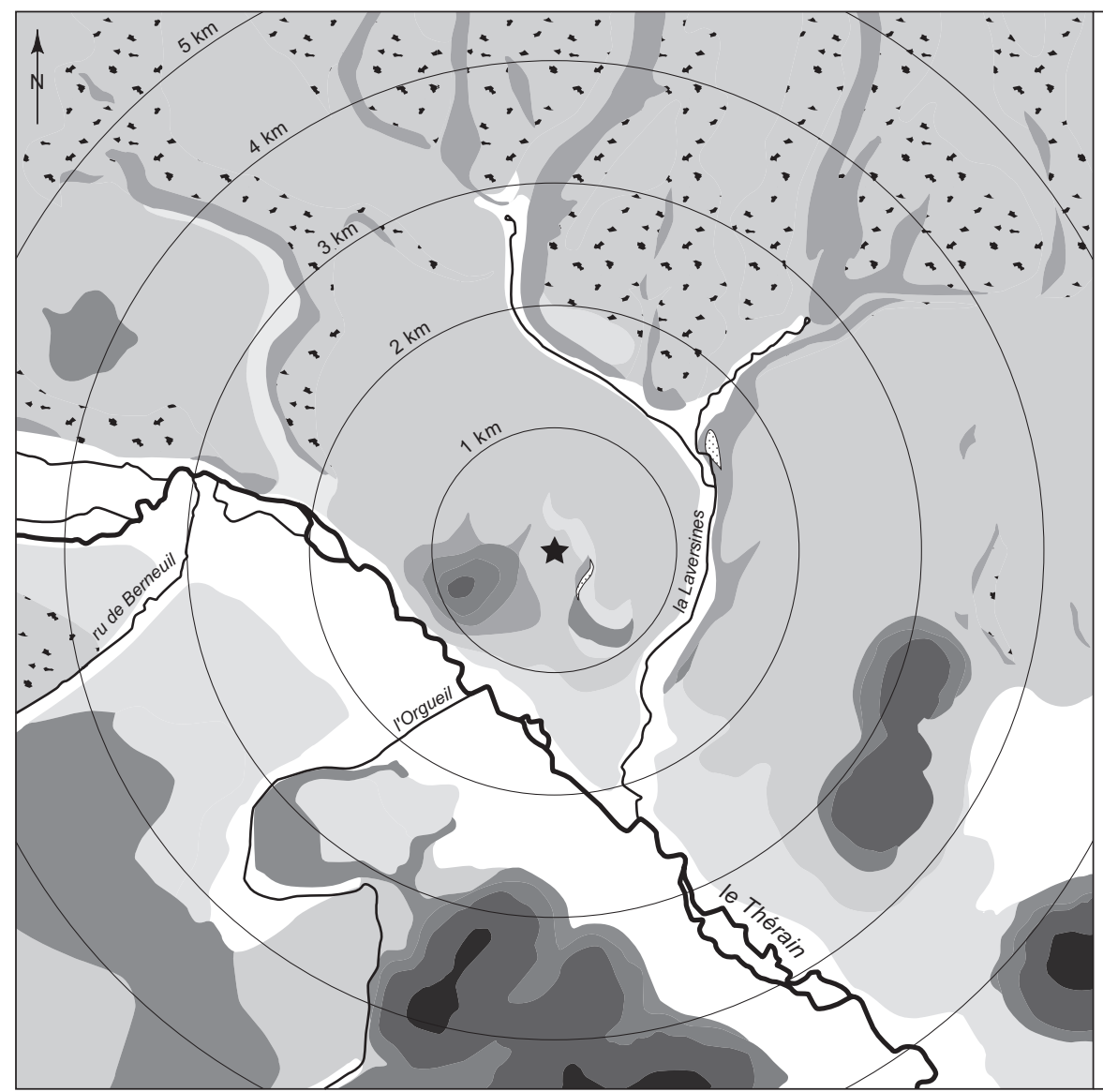

gisement de Therdonne

le mont de Bourguillemont

ح cours d'eau

\section{Formations superficielles}

$\square$ LP/LE : limons bruns de plateau et de pentes - LS/LES : limons brun-rouge à silex et de pentes $\square$ CLP : colluvions de fond de vallées sèches

$\square$ Fx: alluvions anciennes de hauts niveaux

$\square$ Fy : alluvions anciennes de bas niveaux

$\square$ Fz: alluvions modernes

\section{Éocène}

e5 : Lutétien

e4 : Cuisien

e3 : Sparnacien

\section{Paléocène}

e2 : Thanétien

e1 : Montien

\section{Crétacé}

C6 : Campanien, craie à Bélemnitelles

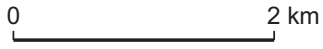

3

Fig. 1 - Localisation du gisement de Therdonne dans son cadre topographique microrégional et dans son cadre géologique (DAO: D. Hérisson, CNRS). 


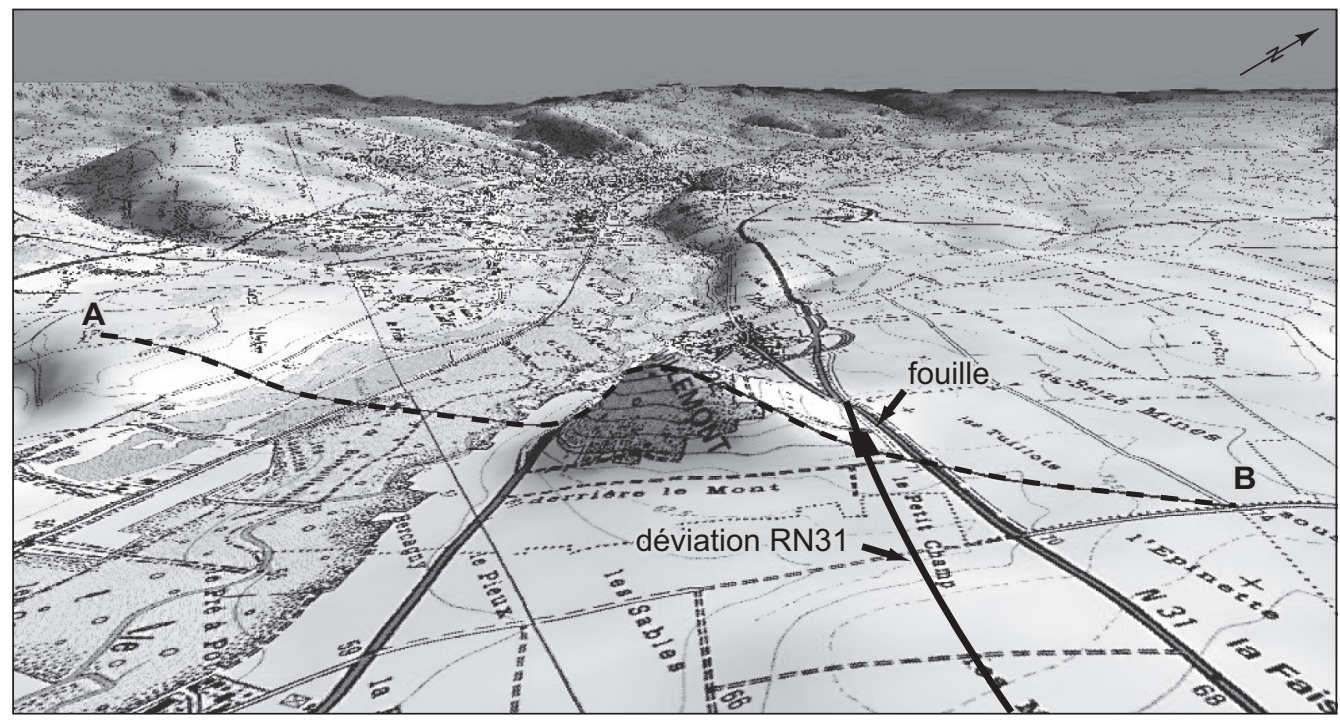

1
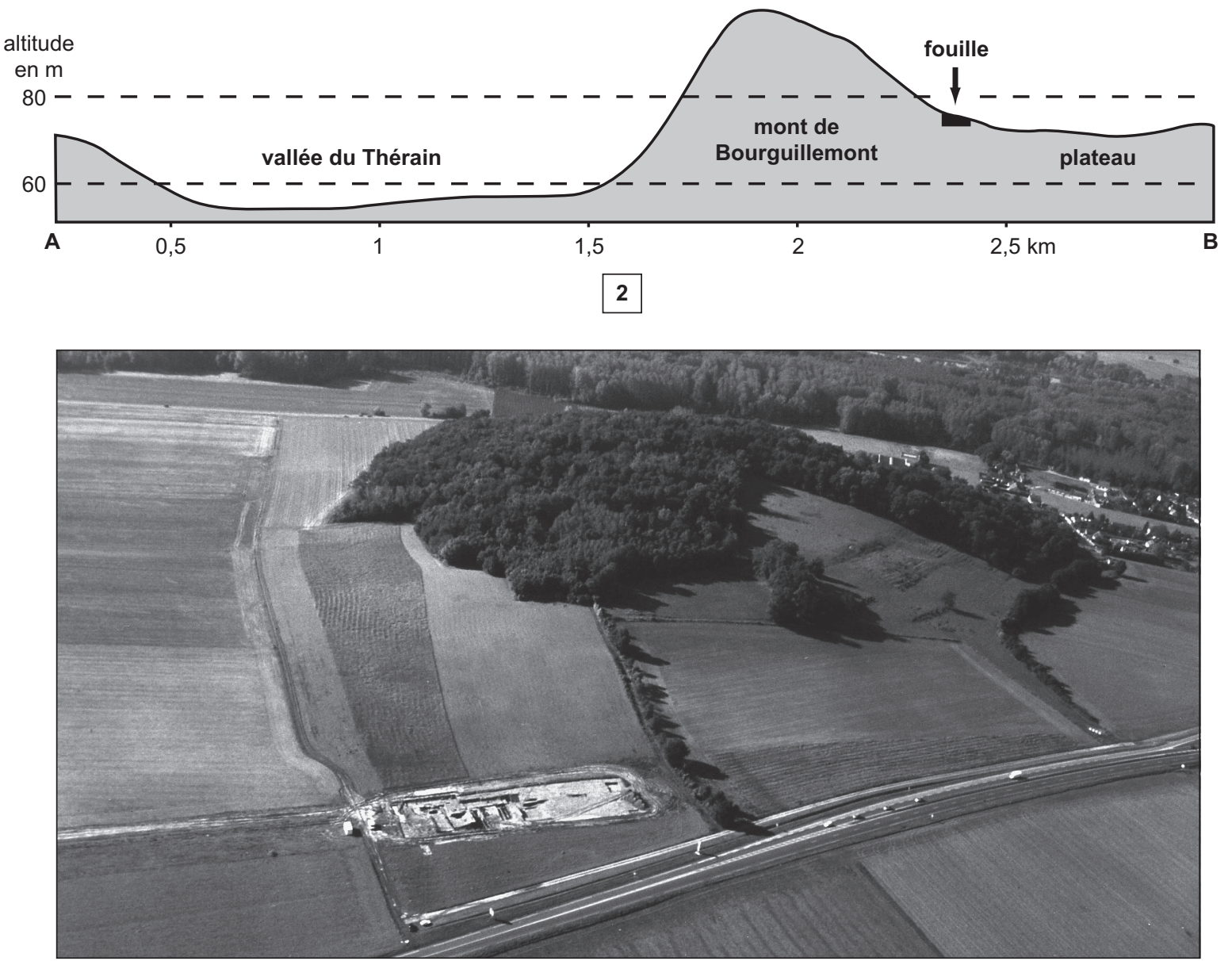

3

Fig. 2 - 1, localisation de la fouille et du profil; 2, profil topographique de la fouille et de ses environs; 3, vue aérienne de la fouille et du mont de Bourguillemont (DAO: D. Hérisson, CNRS; cliché: P. Joy). 


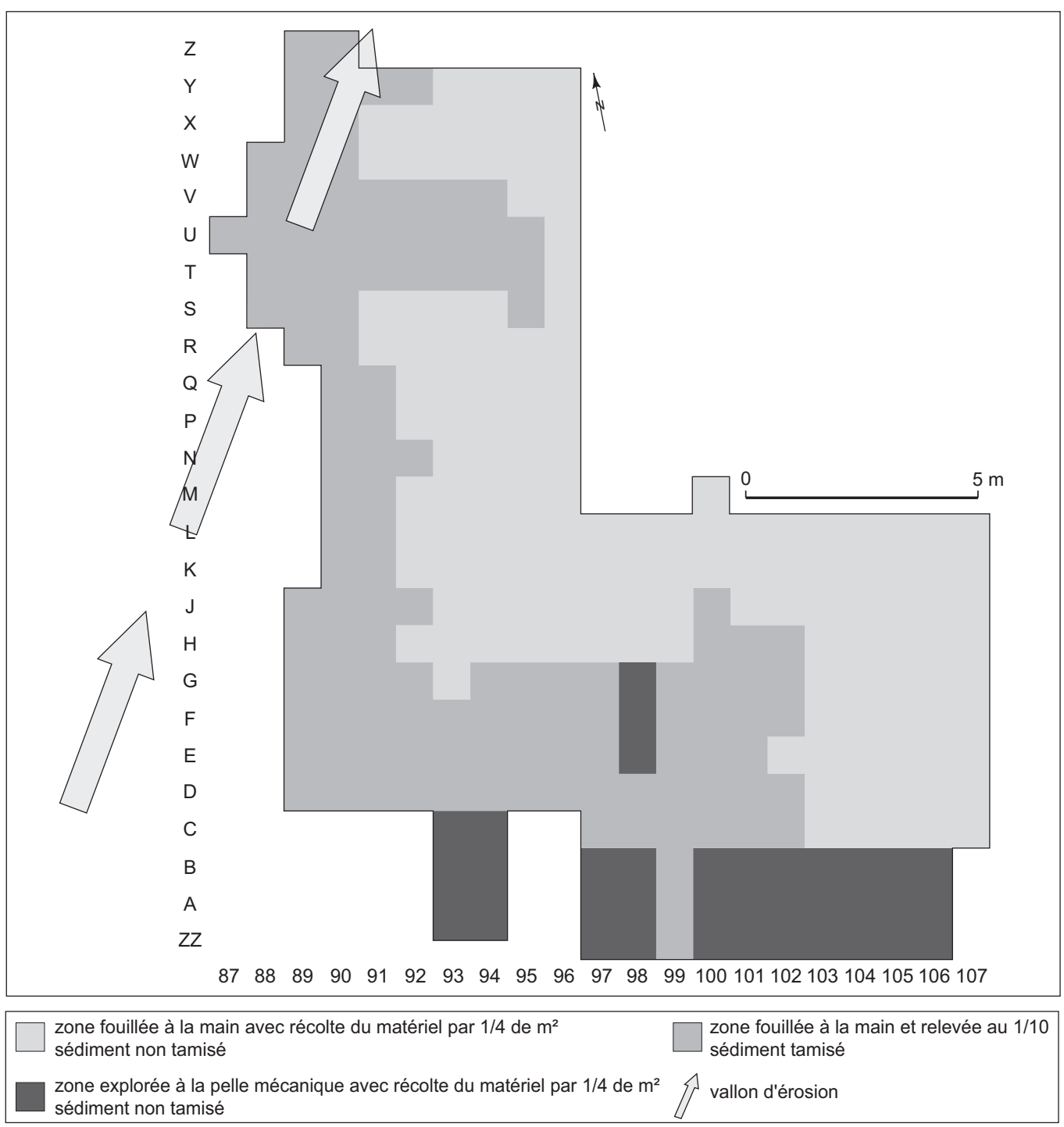

Fig. 3 - Méthode d’intervention et localisation du vallon d'érosion (DAO: D. Hérisson, CNRS).

\section{GYCLE 1}

1. Le cycle 1 débute par une période d'érosion intense, avec création d'une structure en vallon sur le flanc nord de la butte tertiaire par de probables processus de ruissellement concentrés. C'est sur cette surface totalement décapée que s'installent les Paléolithiques (niveau principal N3), dans un contexte proche de celui du site de Beauvais: substrat tertiaire préalablement mis à nu et soumis au processus éolien, absence de développement pédologique antérieur (Locht et al., 1995).

Cette occupation est contemporaine d'une phase aride avec remobilisation du sable par les processus éoliens et développement d'un petit horizon, faiblement humifère SGH (max. 0,2 \% de carbone organique total), de type steppique, que l'on peut observer dans la même position stratigraphique à Mautort dans la Somme (Antoine, 1990) et à Villiers-Adam dans le Val-d'Oise (Locht et al., 1997 et 2003). Quelques restes de microfaune, retrouvés dans le sédiment qui contient le niveau archéologique N3 (deux molaires: une P4 et une M3), ont pu être attribuées à cf. Citellus superciliosus (le Souslik ou Spermophile) par E. Desclaux du Laboratoire de Préhistoire du Lazaret. Il s'agit d'un rongeur inféodé aux steppes continentales dont la présence suggère un climat froid et sec, ainsi qu'un milieu ouvert, en accord avec les données sédi- 

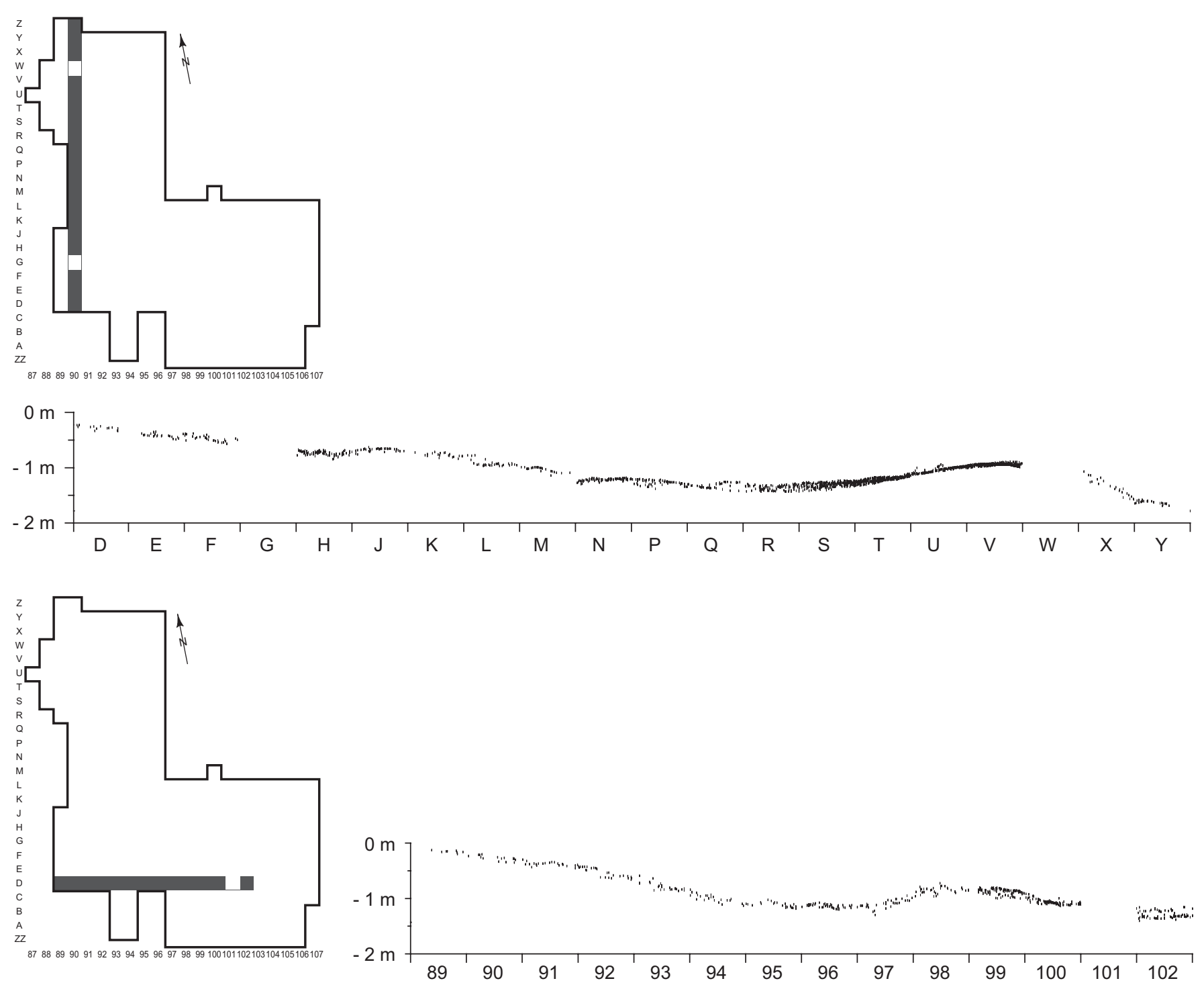

Fig. 4 - Projections verticales des artefacts du niveau N3 (DAO: D. Hérisson, CNRS).

mentologiques. Par ailleurs, trois dents de Boviné ont été découvertes dans la partie sud de la fouille. Leur état de conservation ne permet pas de détermination spécifique plus poussée.

2. La dégradation climatique et le passage à un environnement beaucoup plus froid et humide de type périglaciaire sont attestés par la mise en place des sables limoneux lités SLBL. Cette unité, qui contient localement des lentilles de type lœssique, se caractérise par la présence de microfentes de cryodessication et se termine par une courte stabilisation avec formation d'un gley de toundra souvent déformé par la cryoturbation qui affecte sa moitié supérieure $( \pm 0,5 \mathrm{~m})$. Cette phase d'érosion intense entraîne le remaniement d'une partie de l'occupation principale et la dispersion d'artefacts dans SLBL (niveau N2).

La dégradation climatique se poursuit avec une nette accentuation des processus d'érosion et de sédimentation par ruissellement avec la mise en place de l'unité SAR alimentée par le remaniement des sables et des argiles tertiaires de la butte (couches de nodules d'argile grise millimétriques). Enfin, dans un des profils principaux, de grandes structures correspondant au développement de grandes fentes en coin de type ice-wedges témoignent de l'existence d'un important épisode de permafrost à la fin du cycle 1. Ces structures seront cependant retouchées lors du début du cycle 2 . 
3. Amélioration climatique de rang interglaciaire avec développement d'un sol brun lessivé typique (horizon $\mathrm{Bt}$ ), qui se forme aux dépens du sommet des dépôts SAR (unité LSABR). Cet horizon possède les caractéristiques classiques des horizons Bt attribués au dernier interglaciaire dans la France septentrionale (sol de Rocourt, voir Gullentops, 1954; Antoine et al., 1999).

\section{GYCLE 2}

1. Le cycle 2 débute par l'érosion du sommet du Bt interglaciaire LSABR, et la formation d'un sol de type gris forestier sur colluvions limono-sableuses à charbons de bois épars (LSABH). Cette pédogenèse est cependant fortement dégradée par les processus de gel profond (structure polyédrique à squelettanes) et tronquée par des processus érosifs ultérieurs (2).

2. Une phase de dégradation climatique assez intense se marque ensuite par l'ouverture d'une nouvelle génération de fentes de gel imbriquées dans les premières, mais beaucoup moins importantes. Leur géométrie détaillée est cependant très difficile à établir car elles ont subi ultérieurement une dégradation très poussée de type thermokarstique (fusion de la glace), avec érosion et fluage des bords (Antoine et al., 2001 et 2009). Cette dynamique a abouti à la formation d'un colmatage très hétérogène à blocs et nodules de sols centimétriques à décimétriques remaniés à partir des unités LSABR et LSABH. Un niveau avec quelques pièces paléolithiques a été observé au contact de LSABH/LSAH (N1). Cette partie de la séquence se termine par la mise en place d'une unité sablo-limoneuse plus homogène (apports éoliens), où se développe un petit sol humifère de type steppique (LSAH). D'une manière générale, bien que relativement contracté, le bilan pédosédimentaire représenté par la succession LSABH/LSAH est comparable au bilan du Début Glaciaire weichsélien de la France septentrionale et représente le bilan de l'intervalle \pm 112-70 ka BP (Antoine et al., 1994, 1999 et 2001).

3. Une nouvelle péjoration climatique intense marque ensuite le début d'une nouvelle phase de type pléniglaciaire. Elle se traduit par la succession suivante:

- formation d'un niveau de fines fentes de gel à colmatage humifère (FRH) qui présentent localement une structuration verticale soulignée par des éléments plus grossiers: sable, petit cailloutis typique des fentes de type sand-wedge (French, Gozdzik, 1988; Fisher, 1996);

- érosion intense avec, localement, décapage total de LSAH (alors uniquement préservé dans les fentes);
- mise en place d'une nouvelle génération de dépôts sablo-argileux ruisselés avec niveaux de cryoturbation syngénétique (SBGL), dans un contexte de type pléniglaciaire humide.

4. Après la mise en place de SBGL, la sédimentation devient plus homogène et nettement plus éolienne (contexte plus aride), puis on observe la formation de plusieurs horizons pédologiques peu marqués qui témoignent d'une stabilisation et d'une amélioration climatique relative (unités LSABG/LSABO/LBGH). Cette succession, qui possède de nombreux points communs avec celle de Beauvais dans l'Oise (Locht et al., 1995) et de Villiers-Adam dans le Val-d'Oise (Locht et al., 1997 et 2003), est caractéristique du Pléniglaciaire moyen régional (Antoine et al., 1999 et 2003; Antoine, 2002).

5. Une nouvelle et dernière génération de dépôts limonosableux lités de type périglaciaire se met ensuite en place au sommet de la séquence 2, au début du Pléniglaciaire supérieur weichsélien. Notons, à Therdonne, l'absence de lœess calcaires typiques.

6. Développement d'un sol brun lessivé sur les matériaux précédents au cours du Tardiglaciaire weichsélien et de l'Holocène. Cette unité est cependant fortement tronquée par l'impact anthropique holocène.

Par comparaison avec les séquences régionales (Antoine et al., 1994, 1998 et 2001), cette analyse pédostratigraphique de la séquence de Therdonne montre donc que l'occupation principale N3 de Therdonne se trouve à la base de l'avant-dernier Glaciaire avant le développement des faciès typiquement pléniglaciaires du cycle 1. La corrélation avec les enregistrements paléoclimatiques globaux (Martinson et al., 1987; Petit et al., 1999), nous permet de situer l'occupation N3 dans une phase terminale de l'Interglaciaire intrasaalien (fin du stade isotopique 7a, vers $190 \mathrm{ka} \mathrm{BP}$ ), ou éventuellement au cours d'un interstade relatif du début du stade 6 , vers $170 \mathrm{ka} \mathrm{BP}$, en accord avec les âges obtenus par thermoluminescence pour N3 par N. Debenham $(178 \pm 11$ ka BP $)$.

\section{POSITION GHRONOSTRATIGRAPHIQUE DES INDUSTRIES LITHIQUES}

Quatre niveaux ont été individualisés sur le gisement de Therdonne. Le niveau le plus ancien (N4), constitué d'un peu plus de 250 artefacts, se trouve à l'interface entre les unités SV (sable vert thanétien) et SGH. L'aspect physique de ces artefacts est frais, quoiqu'un peu éolisé. Ils ont sans doute été recouverts assez rapidement et ne seraient 
Tabl. I - Description des principales unités de la séquence de Therdonne, interprétation pédosédimentaire et chronostratigraphique.

\begin{tabular}{|c|}
\hline Description des unités \\
\hline $\begin{array}{l}\text { SV - Sable vert glauconieux homogène avec bandes et linéoles } \\
\text { brunes à orangé et réseau de fissures obliques irrégulières. }\end{array}$ \\
\hline $\begin{array}{l}\text { SGH (P5-P6) - Sable gris-noir homogène à nombreux petits } \\
\text { nodules organo-ferriques, charbons de bois épars et industrie } \\
\text { paléolithique non patinée avec silex chauffés en place (niveau } \\
\text { principal N3). La base de cette unité est localement jalonnée } \\
\text { par un niveau de petits galets épars. Latéralement (P5), ce } \\
\text { niveau passe progressivement à un horizon brun grisâtre } \\
\text { argileux compact, faiblement humifère, avec industrie en place } \\
\text { et silex chauffés (SABH). }\end{array}$ \\
\hline
\end{tabular}
et silex chauffés (SABH).

SLBL - Ensemble de limons sableux bruns à brun-gris finement lités non calcaires comportant localement des lits d'argile grise $(2-3 \mathrm{~mm})$ et des microchenaux. Des artefacts plus ou moins remaniés sont présents à la base et dans la partie médiane de cette unité (P5).

SAR - Ensemble de sables argilo-limoneux bruns à brunrouge à litages très marqués soulignés par des lits $(2-10 \mathrm{~mm})$ de nodules d'argile grise remaniés. La base de cette unité est localement soulignée par un cailloutis de silex et de petits blocs de grès ferrugineux.

LSABR - Limon sablo-argileux compact brun-rouge à brun orangé à structure polyédrique, nombreuses taches d'hydromorphie (plages grises irrégulières), revêtements argileux épais, nombreux biotubules et logettes (vers). Cette unité est pénétrée par de grandes structures subverticales à remplissage hétérogène (RFH).

RFG - Remplissage hétérogène des grandes fentes irrégulières visibles en $\mathrm{P} 3$ et P4, constitué par une accumulation de blocs et nodules limoneux irréguliers centimétriques brun-gris à brun orangé emballés dans une matrice limoneuse grise humifère finement litée.

LSABH - Limon sablo-argileux compact brun grisâtre à taches d'oxydation éparses, structure polyédrique millimétrique $(3-5 \mathrm{~mm})$ très marquée, logettes d'hibernation et nombreux biotubules (vers) et rares charbons de bois et nodules organoferriques épars.

LSAH-FRH - Limon sablo-argileux brun grisâtre à taches jaunes (dégradation de la matière organique), homogène, humifère, à structure granulaire fine. Cette unité est en grande partie piégée (remaniée) dans le remplissage des fentes qui affectent la partie supérieure du complexe LSABR/LSABH. Le colmatage de ces fentes se caractérise par une stratification subverticale avec accumulation d'éléments grossiers (petits silex, nodules organo-ferriques remaniés, 1-4 mm).

SBGL - Sable limoneux brun grisâtre, non calcaire, fortement lité à niveaux argileux gris (lits de nodules argileux millimétriques), avec localement quelques traces de cryoturbation. La base de cette unité est soulignée par un cailloutis de silex et de grès ferrugineux (CX).

LSABG - Limon sablo-argileux brun grisâtre faiblement humifère, compact, avec nombreuses traces de carbonatation secondaire (tubules et pseudomycelium).

LSABO - Limon sablo-argileux brun orangé à structure granulaire fine, avec abondantes traces de recarbonatation (tubules et pseudomycelium), nodules organo-ferriques épars.

LBGH - Limon brun grisâtre faiblement humifère avec nombreux tubules calcaires et pseudomycelium.

SLBJ - Sables limoneux non calcaires fortement lités brunjaune à lits argileux gris (nodules ruisselés).

seudomorphoses de grandes fentes à coins de glace fortement dégradées par des processus thermokarstiques (dégradation des coins de glace), remplies par des produits d'érosion des parois (blocs gelés). Localement, la partie centrale de ce remplissage a piégé le faciès humifère LSAH (P3). L'ensemble est colmaté par des sédiments montrant localement des microfigures de ruissellement liées à la percolation en profondeur de matériaux limoneux humifères érodés en surface.

Horizon de type Bth de sol gris forestier, fortement érodé et affecté par une structure de gel saisonnier profond.

Horizon isohumique de type "steppique ", sans illuviation d'argile, développé sur un matériau colluvial sablo-limoneux d'origine locale. Cette unité est piégée ultérieurement lors de l'ouverture du réseau de fentes de type sand-wedge au sommet de LSAH. La partie supérieure des fentes est généralement tronquée lors de la phase d'érosion qui souligne la base de SBGL (cailloutis $\mathbf{C X}$ ).

Dépôts lités mis en place par ruissellement, alimentés par le remaniement des formations tertiaires de la butte (lits de nodules d'argile grise) et des dépôts antérieurs (sols LSABR/LSABH et dépôts ruisselés SAR) (troisième génération de dépôts ruisselés).

Matériau d'origine éolienne à forte charge locale (déflation sur la butte sableuse tertiaire) avec faible pédogenèse de type sol de prairie arctique.

Horizon de type Bw (" sol brun arctique »/Cambisol) sur matériau sablo-limoneux d'origine éolienne à forte charge locale (déflation sur la butte sableuse tertiaire). Faciès type du sol de Villiers-Adam.

Petit horizon isohumique de type sol de prairie arctique.

Dépôts lités mis en place par ruissellement à partir des formations tertiaires de la butte (lits de nodules d'argile grise) et des dépôts antérieurs (dernière génération de dépôts ruisselés).

LABR (P1) - Limon argileux brun non calcaire, compact à Horizon Bt du sol brun lessivé de surface tronqué par les Tardiglaciaire / Holocène structure prismatique grossière et revêtements argileux brun- travaux. rouge dans les biotubules.

\begin{tabular}{|c|c|}
\hline $\begin{array}{c}\text { Chronostratigraphie } \\
\text { / Âge }\end{array}$ & $\begin{array}{c}\text { Niveau } \\
\text { archéologique }\end{array}$ \\
\hline Thanétien & \\
\hline \multirow[t]{3}{*}{$\begin{array}{l}\text { Fin de l'Interglaciaire } \\
\text { intrassalien } \\
\text { (stade isotopique } 7 \\
\text { c. } 170-190 \mathrm{ka} \text { ) }\end{array}$} & $\begin{array}{c}\text { Niveau principal } \\
\text { N3 et niveau } \\
\text { inférieur N4 }\end{array}$ \\
\hline & Niveau N2 \\
\hline & $\begin{array}{l}\text { Artefacts } \\
\text { remaniés }\end{array}$ \\
\hline $\begin{array}{c}\text { Interglaciaire Eemien } \\
\text { (sous-stade isotopique } 5 \mathrm{e}, \\
112-128 \mathrm{ka} \text { ) avec } \\
\text { surimposition de } \\
\text { structures pédologiques } \\
\text { et de ségrégation de } \\
\text { glace attribuables } \\
\text { au Début Glaciaire } \\
\text { weichsélien } \\
\text { (sous-stades 5a-5d) }\end{array}$ & \\
\hline $\begin{array}{c}\text { Pléniglaciaire inférieur } \\
(60-70 \mathrm{ka}) \\
\text { probablement composite : } \\
\text { une phase initiale } \\
\text { fin Saalien, une } \\
\text { phase pléniglaciaire } \\
\text { inférieur suivie d'une } \\
\text { phase de dégradation } \\
\text { (thermokarst) }\end{array}$ & \\
\hline $\begin{array}{c}\text { Début Glaciaire } \\
\text { weichsélien (phase à } \\
\text { sols gris forestier, } \\
\text { sous-stades } 5 \mathrm{~d}-5 \mathrm{a}, \\
\text { c. } 112-70 \mathrm{ka} \text { ) }\end{array}$ & \\
\hline $\begin{array}{l}\text { LSAH - Début Glaciaire } \\
\text { weichsélien, phase à } \\
\text { sols steppiques vers } \\
68-70 \text { ka (LSAH) } \\
\text { FRH - Pléniglaciaire } \\
\text { inférieur, début du stade } \\
\text { isotopique } 4 \\
\text { c. } 65-70 \text { ka BP (FRH) }\end{array}$ & $\begin{array}{l}\text { Artefacts } \\
\text { remaniés }\end{array}$ \\
\hline $\begin{array}{l}\text { Pléniglaciaire inférieur } \\
\text { (c. } 55-50 \mathrm{ka} \text { ?) }\end{array}$ & $\begin{array}{l}\text { Artefacts } \\
\text { remaniés } \\
\text { Niveau N1 }\end{array}$ \\
\hline Pléniglaciaire moyen? & \\
\hline $\begin{array}{l}\text { Pléniglaciaire moyen } \\
\text { (c. } 45-50 \mathrm{ka} \text { ) }\end{array}$ & \\
\hline $\begin{array}{l}\text { Pléniglaciaire moyen } \\
\text { (c. } 45-40 \mathrm{ka} \text { ) }\end{array}$ & \\
\hline $\begin{array}{l}\text { Pléniglaciaire moyen } \\
\text { (c. } 40-35 \mathrm{ka} \text { ) }\end{array}$ & \\
\hline Tardiglaciaire / Holocène & \\
\hline
\end{tabular}




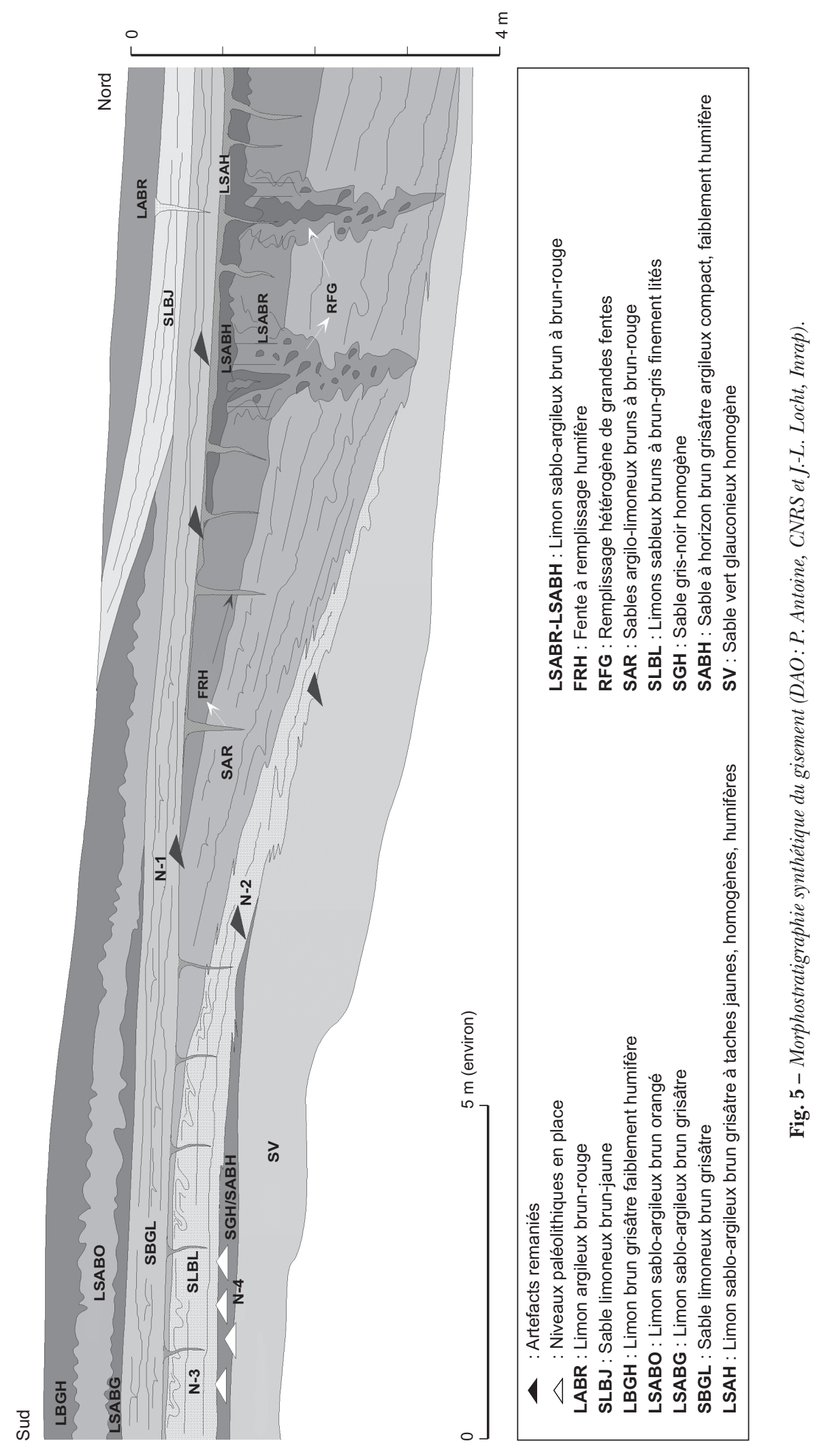


guère éloignés chronologiquement de la principale occupation N3 (fig. 5).

En position stratigraphique similaire à celle de N4, et dans quelques cas inférieure en altitude, 9 pièces bifaciales ont été retrouvées. Toutefois, leur aspect physique les différencie de N4, par leur patine profonde et les nombreuses traces de gélifraction qui les affectent.

Le niveau paléolithique principal (N3) est contenu dans un niveau de sable éolien affecté par une pédogenèse humique (SGH). Les datations TL sur quatre silex chauffés du niveau N3 ont été réalisées par N. Debenham et ont donné un âge moyen de $178 \pm 11$ ka BP, ce qui est en accord avec les données pédostratigraphiques et permet de replacer cette occupation à la fin du stade isotopique 7a, à la fin de l'Interglaciaire intrasaalien, vers 170-190 ka (Locht et al., 2000, p. 49-53).

Les sables ruisselés de la première (SLBL) et de la seconde génération (SAR) contiennent un matériel lithique (N2 = 302 artefacts) qui n'est pas en place d'un point de vue archéologique. Il s'agit vraisemblablement d'artefacts du niveau N3 démantelés, localisés initialement plus haut sur le versant. La parenté technotypologique entre N3 et N2 renforce cette hypothèse.

Enfin, le profil $\mathrm{P} 4$ a livré près de 430 artefacts contenus dans un sol de type gris forestier (N1), contemporains du Début Glaciaire weichsélien. Latéralement, ce sol disparaît assez rapidement, et les artefacts sont retrouvés en position remaniée à la base de l'unité SGBL, ou parfois associés à un cailloutis.

\section{ÉTUDE PRÉLIMINAIRE DE L'INDUSTRIE LITHIQUE DU NIVEAU N3}

\section{LES MATIÈRES PREMIÈRES LITHIQUES EXPLOITÉES}

Le site de Therdonne s'inscrit pleinement dans le cadre géologique riche en matière première siliceuse de la France septentrionale. La quasi-intégralité de la production de l'industrie lithique a été effectuée à partir de rognons ramassés à proximité immédiate du gisement. En effet, les gîtes de matière première, aujourd'hui encore en partie accessibles, sont situés dans un rayon inférieur à $2 \mathrm{~km}$ (fig. 1, n 3). Trois types de matériaux ont été exploités par les Préhistoriques: le silex campanien à cortex crayeux, le silex tertiaire à cortex verdi et les galets avellanaires.

\section{LE SILEX CAMPANIEN À CORTEX CRAYEUX}

L'examen du silex à cortex crayeux a indiqué qu'il s'agissait d'un silex campanien (Locht, 2004). Il affleure entre le pied de la butte et le plateau (Locht et al., 2000), ce qui facilite les activités de taille directement sur le site (fig. 1, n 3). Il est également présent un peu plus loin notamment le long des versants du Thérain en quantité abondante. Le cortex rugueux à lisse, toujours crayeux, présente une épaisseur inframillimétrique à supramillimétrique. La couleur corticale varie du blanc au rosé en passant par le beige. La matrice noire est chargée de plages de silicification incomplètes blanchâtres. La majorité des pièces campaniennes de la série s'est patinée de manière inverse (matrice gris clair et inclusions gris-noir). Le silex campanien à cortex crayeux se prête relativement bien à la taille, la présence de nombreuses inclusions n'affectant pas la propagation des ondes et n'entraînant pas une fracturation anormale.

\section{LE SILEX TERTIAIRE À CORTEX VERDI}

Le silex à cortex verdi se retrouve dans les formations tertiaires du Thanétien (fig. 1, n 3 ). La glauconie présente dans les sables tertiaires a entraîné l'altération de la surface corticale, créant une teinte verdâtre caractéristique. Le silex campanien à cortex verdi se trouve également bien représenté aux abords immédiats du site, à la base des sables tertiaires, ainsi que sur le territoire proche où on le trouve régulièrement en surface sur les versants comme aux pieds des collines tertiaires (Locht et al., 2000). Le cortex inframillimétrique non crayeux possède une couleur ocre jaune à passages verdâtres. La matrice noire est le plus souvent très chargée en inclusions blanchâtres. Comme pour le silex campanien, la majorité des pièces tertiaires à cortex verdi de la série s'est patinée de manière inverse (matrice gris clair et inclusions gris-noir). Les rognons tertiaires à cortex verdi présentent une excellente aptitude à la taille. Ce sont ces blocs que les Préhistoriques ont nettement privilégiés afin de produire leurs outils lithiques.

\section{LES GALETS AVELLANAIRES}

Les galets avellanaires se trouvent dans le sable thanétien en place (Locht et al., 2000). Ils sont donc directement accessibles sur le site. Les galets avellanaires sont des blocs de petites dimensions $(<10 \mathrm{~cm})$ et de mauvaise qualité, qui n'offrent pas les qualités de fracturation et de développe- 
Tabl. II - Décompte et pourcentage des différentes catégories d'artefacts du niveau N3.

\begin{tabular}{|l|r|r|c|c|}
\hline \multicolumn{1}{|c|}{ Catégorie } & Nombre & $\begin{array}{c}\% \\
\text { du total }\end{array}$ & $\begin{array}{c}\text { \% } \\
\text { sans esquilles }\end{array}$ & $\begin{array}{c}\text { \% sans esquilles } \\
\text { et sans éclats < } \mathbf{~ c m}\end{array}$ \\
\hline $\begin{array}{l}\text { Éclats corticaux } \\
\text { (+ de 50 \% de cortex) }\end{array}$ & 1027 & 2,08 & 7,39 & 12,83 \\
\hline $\begin{array}{l}\text { Éclats corticaux } \\
\text { (- de 50 \% de cortex) }\end{array}$ & 2147 & 4,36 & 15,44 & 26,82 \\
\hline Éclats & 4120 & 8,36 & 29,64 & 51,47 \\
\hline Éclats Levallois & 213 & 0,43 & 1,53 & 2,66 \\
\hline Pointes Levallois & 125 & 0,25 & 0,90 & 1,56 \\
\hline Éclats allongés et lames & 73 & 0,15 & 0,53 & 0,91 \\
\hline Éclats débordants & 71 & 0,14 & 0,51 & 0,89 \\
\hline Pointes pseudo-Levallois & 21 & 0,04 & 0,15 & 0,26 \\
\hline Cassons & 133 & 0,27 & 0,96 & 1,66 \\
\hline Nucléus & 69 & 0,14 & 0,50 & 0,86 \\
\hline Blocs testés & 6 & 0,01 & 0,04 & 0,07 \\
\hline Éclats de moins de $3 \mathrm{~cm}$ & 5896 & 11,96 & 42,41 & - \\
\hline Esquilles & 35391 & 71,80 & - & $\mathbf{1 0 0 , 0 0}$ \\
\hline Total & $\mathbf{4 9} \mathbf{2 9 2}$ & $\mathbf{1 0 0 , 0 0}$ & $\mathbf{1 0 0 , 0 0}$ & \\
\hline
\end{tabular}

ment de l'onde de fracturation requises généralement pour les roches siliceuses lors des activités de taille. De plus, ces galets sont aussi souvent gélivés. Tous ces éléments expliquent qu'ils ont été exploités de manière anecdotique par les Préhistoriques.

\section{UN MARQUEUR DE DÉPLACEMENT ORIGINAL}

Un petit bloc de grès de forme parallélépipédique a été retrouvé lors de la fouille du niveau N3. Son examen par J. Fabre, université d'Amiens, a montré qu'il s'agissait d'un grès fin ferrugineux à laminations millimétriques horizontales et obliques qui se distingue du grès habituellement découvert dans les niveaux thanétiens affleurant en quantité dans un rayon relativement proche du site (Locht $e t$ al., 2000, p. 29). Il pourrait provenir des niveaux auversiens localisés à un peu plus de 12/13 kilomètres à l'est du site.

\section{DÉCOMPTE ET PRÉSENTATION DU NIVEAU N3}

\section{DÉCOMPTE ET CARACTÉRISTIQUES DE LA SÉRIE}

Le niveau N3 représente la principale phase d'occupation du gisement. Près de 50000 artefacts ont été mis au jour lors de la fouille. L'ensemble est largement dominé par plus de 35000 esquilles représentant à elles seules plus de $71 \%$ de la série (tabl. II). Viennent s'ajouter à ces nom- breuses esquilles près de 6000 éclats de petites dimensions $(<3 \mathrm{~cm})$, représentant ensemble plus de $83 \%$ de l'industrie lithique (éclats $<3 \mathrm{~cm}$ et esquilles). L'importance numérique de ces petits artefacts peut notamment s'expliquer par la préparation minutieuse des plans de frappe en chapeau de gendarme de grandes dimensions sur les nucléus Levallois et par l'exploitation des nucléus jusqu'à exhaustion. Les esquilles et les éclats de moins de $3 \mathrm{~cm}$ déduits, l'industrie lithique est principalement composée d'éclats non corticaux et corticaux (respectivement 51,5\% et $39,7 \%$ de la série sans les esquilles et les éclats de moins de $3 \mathrm{~cm}$ ). C'est incontestablement du côté des objectifs de production que l'industrie se particularise. Les deux principaux objectifs sont des éclats Levallois d'une part $(\mathrm{n}=213)$ et des pointes Levallois d'autre part $(\mathrm{n}=125)$. De par leurs dimensions, les pointes Levallois sont sans doute les artefacts les plus remarquables de cette série. La question de leur production in situ peut être raisonnablement posée, eu égard à l'absence totale de nucléus ayant pu produire ces pointes. À l'importance numérique des produits de l'industrie lithique devrait être corrélé un nombre conséquent de nucléus. Or, seuls 69 nucléus ont été mis au jour sur la surface fouillée, représentant à peine $0,14 \%$ de la série et moins de $1 \%$ du total sans les esquilles et les éclats de moins de $3 \mathrm{~cm}$. En comparaison avec les dimensions de certains produits prédéterminés, les nucléus de la série semblent avoir subi une importante phase de réduction. 


\section{LES CHAÎNES OPÉRATOIRES}

Trois chaînes opératoires coexistent pour le niveau N3 de Therdonne: une chaîne opératoire à lames, une chaîne opératoire à éclats et une chaîne opératoire à pointes (Hérisson, 2007, p. 43-93). Les trois chaînes opératoires ont été réalisées in situ comme le prouve, entre autres, le nombre impressionnant d'esquilles retrouvées lors de la fouille. Seul le cas de l'absence de nucléus Levallois à pointe reste à clarifier pour affirmer que la chaîne opératoire à pointes est complète.

La chaîne opératoire à lames est anecdotique avec seulement trois nucléus et un nombre très réduit de lames retrouvées (fig. 6). Les trois nucléus sont exploités exclusivement par une modalité bipolaire. L'objectif de production est l'obtention de lames, c'est-à-dire d'éclats allongés munis de deux bords subparallèles tranchants. Il convient de préciser que le nucléus $n^{\circ} 2$ de la figure 6 présente une surface altérée par un phénomène d'éolisation et a été retrouvé à la base des sables éoliens. Ce nucléus est donc peut-être légèrement antérieur au niveau d'occupation N3.

La chaîne opératoire à éclats se divise en trois chaînes menées par un débitage faiblement prédéterminé, un débitage discoïde et un débitage Levallois. Les nucléus faiblement prédéterminés sont numériquement les plus nombreux mais les moins productifs, avec en moyenne six éclats produits par nucléus (fig. 7, n ${ }^{\text {os }} 1-3$ ). Ce débitage faiblement prédéterminé est majoritairement représenté par des nucléus à un plan de frappe et une surface de débitage, et des nucléus à deux plans de frappe et une surface de débitage. Les produits recherchés sont des éclats de morphologie variée, de faibles dimensions, à bords tranchants, présentant l'avantage d'être produits quasi instantanément sans préparation spécifique. Les sept nucléus discoïdes ont été préférentiellement exploités sur deux surfaces. Avec seulement une vingtaine d'éclats issus de nucléus discoïdes (éclats débordants, pointes pseudo-Levallois et éclats larges; Locht, 2004, p. 45-46), il est difficile d'appréhender l'objectif du débitage discoïde pour le moment. Le débitage Levallois domine le débitage prédéterminé autant en nombre de produits recherchés (213 éclats Levallois typiques) qu'en nombre de nucléus (25 nucléus Levallois). Ces nucléus ont été exploités en majorité par des modalités récurrente centripète et récurrente unipolaire (fig. 7, $\left.\mathrm{n}^{\text {os }} 4-6\right)$. La production d'éclats Levallois préférentiels afin d'obtenir de grands éclats tranchants plus ou moins ovalaires est un des objectifs de production de cette chaîne. Le second objectif vise à produire des éclats à bords tranchants de morphologie contrôlée.

La chaîne opératoire à pointes est dominée par l'utilisation de modalités Levallois unipolaire convergente et bipolaire. Jusqu'à présent, cette chaîne n'était représentée que par un nombre conséquent de pointes Levallois et aucun nucléus ou artefact appartenant à la chaîne opératoire à pointes n'avait été identifié. Un éclat de ravivage de plan de frappe a pu être rattaché à cette chaîne et a permis ainsi de livrer d'importantes informations concernant le débitage des pointes. L'objectif du débitage est l'obtention d'éclats triangulaires calibrés de grandes dimensions à l'extrémité distale pointue (Gadebois, 2006, p. 66-103).

\section{L'OUTILLAGE RETOUCHÉ}

Malgré le nombre conséquent de supports produits, seule une dizaine d'éclats ont été retouchés, majoritairement en racloirs (fig. 8).

\section{RÉPARTITION AU SOL DU MATÉRIEL LITHIQUE ET «ZONES DE COMBUSTION»}

Le niveau N3 a été fouillé sur une surface continue de $305 \mathrm{~m}^{2}$. La densité moyenne des vestiges s'élève à un peu plus de 161 artefacts par mètre carré. Mis à part les quelques restes de microfaune et les trois dents de Boviné, aucun élément de faune n'a été conservé à cause de la décarbonatation du sédiment. D'après les premiers plans d'isodensité par mètre carré des vestiges, des concentrations de matériel s'individualisent (fig. 9 et 10). Une des grandes caractéristiques du niveau N3 est de posséder un grand nombre de silex chauffés ( $n=1593$ ), soit tout de même 3,23 \% de l'ensemble de la série et plus de $11 \%$ en excluant les esquilles. À ces silex chauffés, sont associées plusieurs «zones de combustion». Ces zones repérées au cours de la fouille se caractérisent par un sable très brun, chargé en manganèse et en charbon de bois, dans la partie sud du chantier (fig. 9). Une étude en cours a pour double objectif de définir le rôle et la fonction de ces structures s'apparentant à des foyers non construits et de caractériser la place qu'elles occupent dans le fonctionnement de l'occupation. 

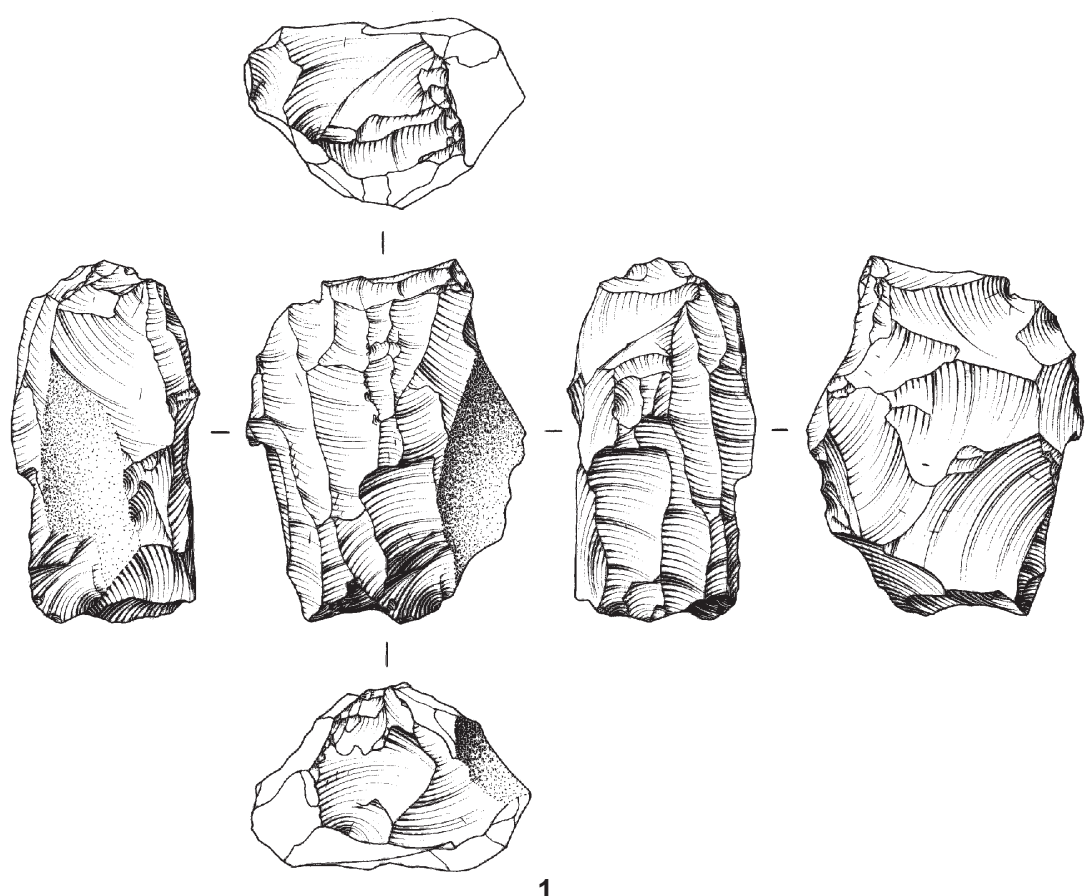

1
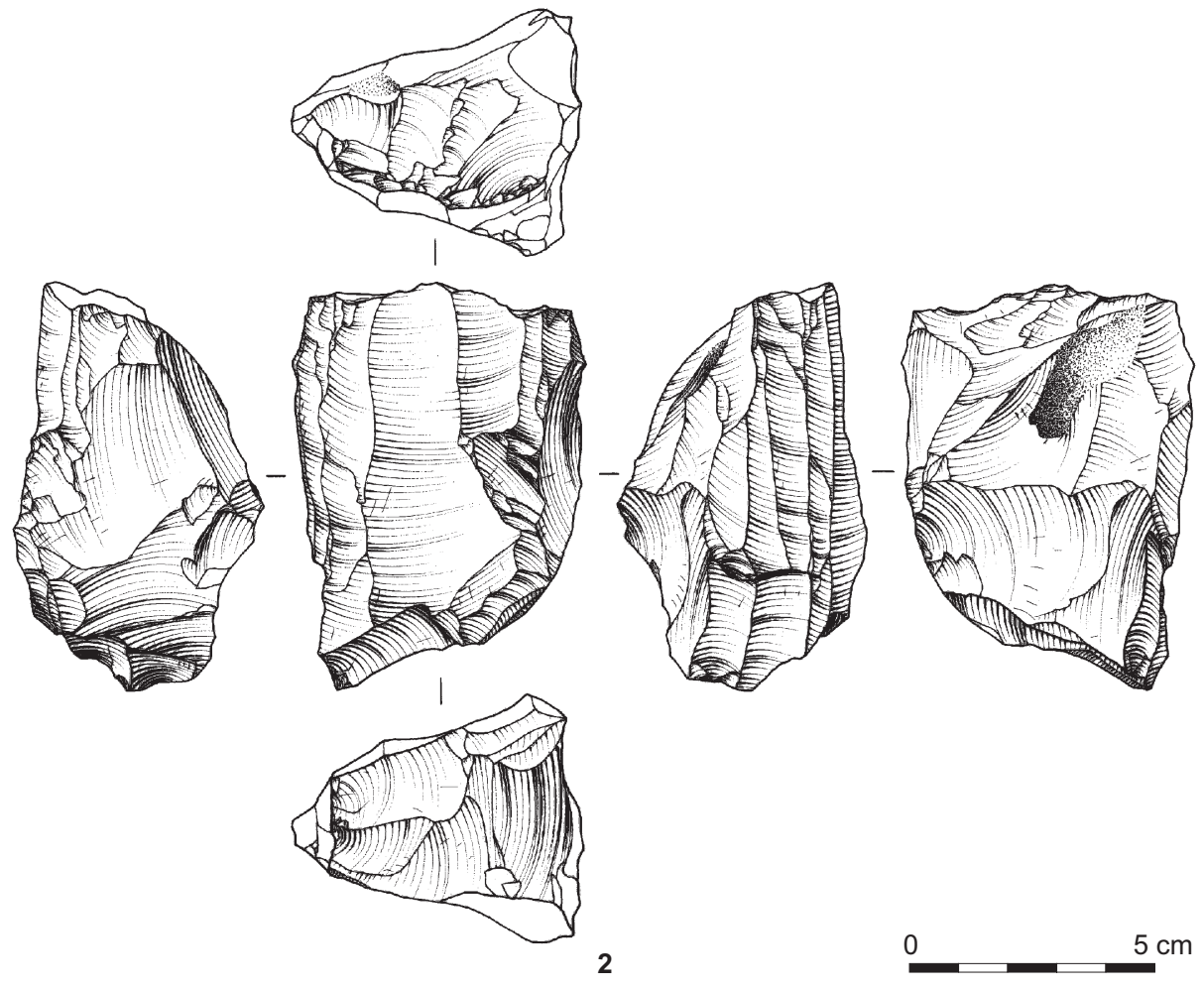

Fig. 6 - Nucléus laminaires bipolaires (dessin: S. Lancelot, Inrap). 

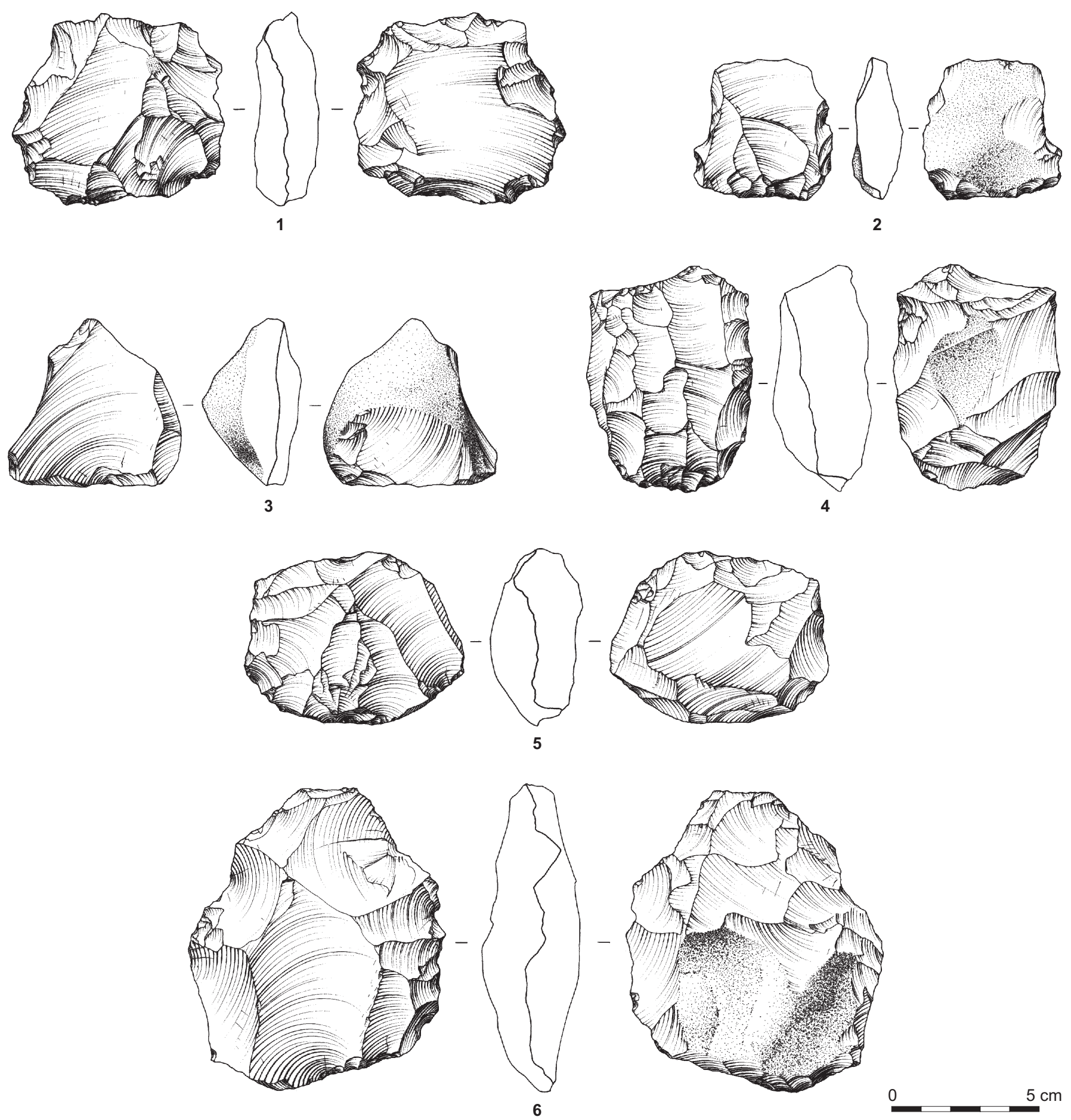

Fig. 7 - 1, nucléus centripète sur éclat; 2, 3, nucléus unipolaires; 4, nucléus Levallois bipolaire; 5, nucléus Levallois unipolaire convergent; 6, nucléus Levallois à éclat préférentiel (dessin: S. Lancelot, Inrap). 

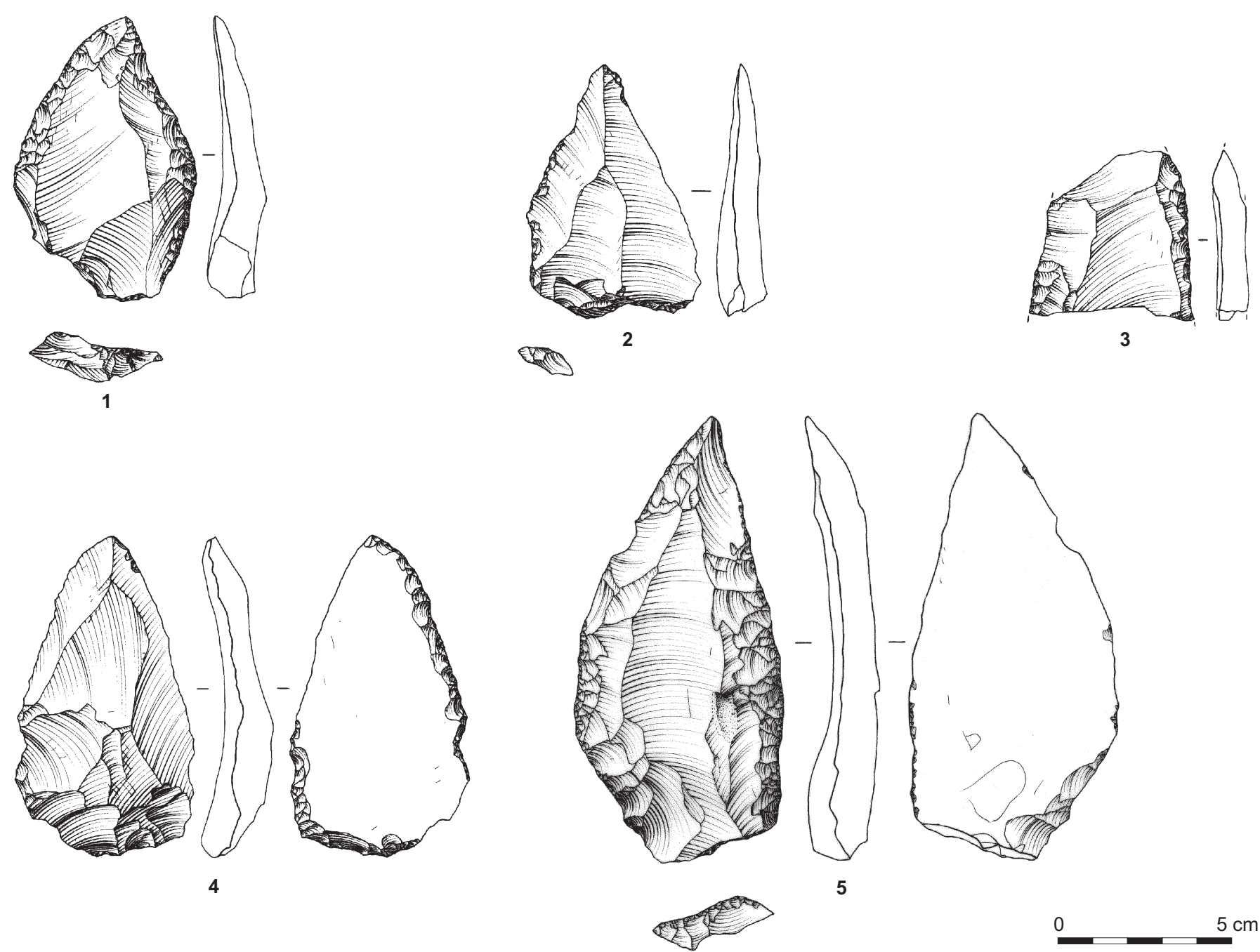

5

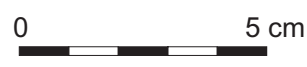

Fig. 8 - Outils retouchés: 1, racloir double convergent; 2, 4, pointes Levallois retouchées; 3, racloir double;

5, pointe moustérienne (dessin: S. Lancelot, Inrap).

\section{LA PRODUCTION DES POINTES ET LA RÉDUCTION DES NUGLÉUS}

\section{CARACTÉRISTIQUES TECHNOLOGIQUES ET MORPHOMÉTRIQUES DES POINTES LEVALLOIS}

Seules les 87 pointes entières ont été prises en compte dans cette caractérisation technologique et morphométrique afin de garder un échantillon homogène pour l'ensemble des études menées.

\section{Caractéristiques technologiques des pointes}

L’approche méthodologique privilégiée lors de l'étude du matériel est principalement technologique, consistant en une lecture directe sur la surface supérieure des négatifs d'enlèvements et de leur agencement préformant la pointe sur la surface d'exploitation du nucléus avant le débitage.

Trois technotypes de pointes Levallois ont été identifiés (tabl. III). Le groupe des pointes construites, avec 52 représentants, est le technotype le mieux représenté 


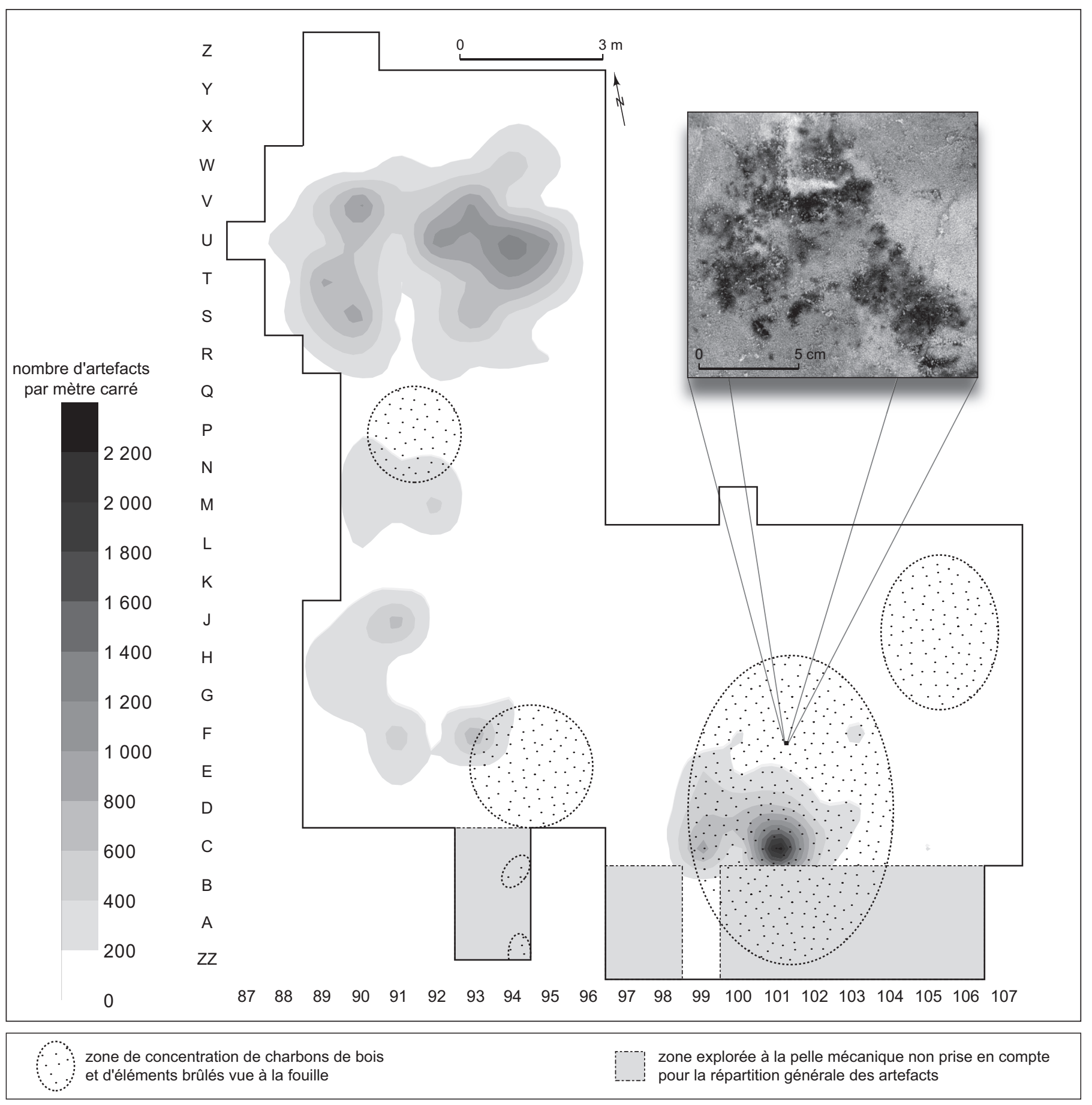

Fig. 9 - Plan de répartition par isodensité de l'ensemble des artefacts du niveau N3, localisation des zones de concentration de charbons de bois et d'éléments brûlés vues à la fouille et photographie d'un détail de l'une de ces zones (DAO: D. Hérisson, CNRS; cliché: J.-L. Locht, Inrap).

(60\% des pointes entières). Ces pointes construites sont issues de modalité de débitage nécessitant l'enchaînement ou la succession de plus de trois coups pour préformer le produit sur le nucléus avant son extraction (Boëda, 1982;
Boëda et al., 1998). La méthode dite «classique» en trois coups a permis l'obtention de 34 pointes, soit $39 \%$ des pointes entières (Bordes, 1961, p. 32-34; Inizan et al., 1995, p. 68-69). Le troisième technotype n'est représenté que par 

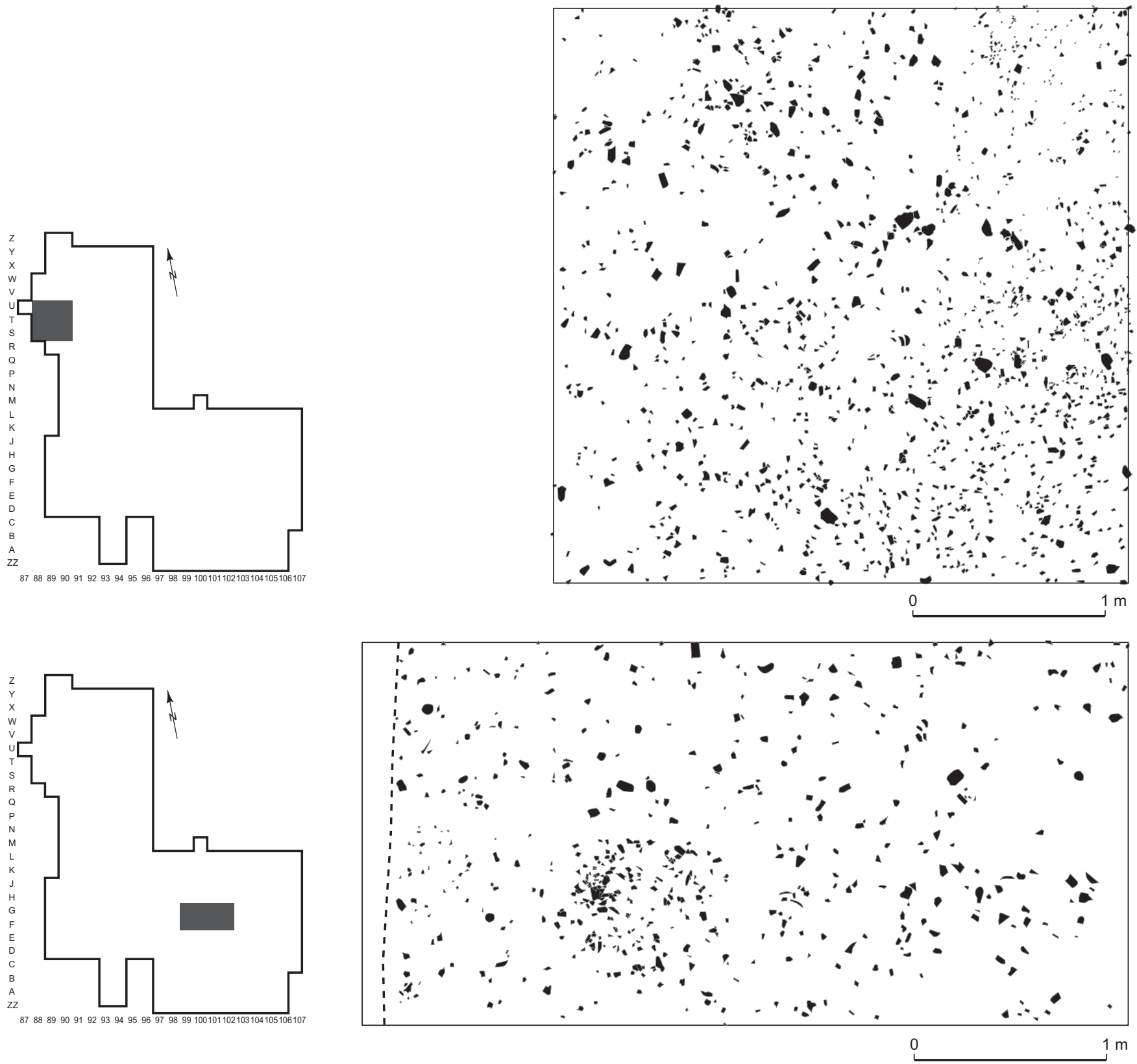

Fig. 10 - Plan de répartition de l'ensemble des artefacts du niveau N3 de deux zones de la fouille (DAO: D. Hérisson, CNRS).

un seul exemplaire, une pointe Levallois de premier ordre (Bordes, 1961, p. 32-34).

$\mathrm{Si}$ le concept qui régit la réalisation des pointes est Levallois, leur étude technologique indique la coexistence de plusieurs modalités de production (Boëda, 1994). Deux modalités ont été privilégiées à Therdonne par les Préhistoriques pour produire les pointes (tabl. III). La plus utilisée, la modalité unipolaire convergente, a permis l'extraction de 47 individus, soit $54 \%$ des pointes entières (fig. 11). La modalité bipolaire opposée a été utilisée pour produire 26 éléments, soit $30 \%$ des pointes entières (fig. 12). Enfin, la production de 14 artefacts, soit $16 \%$ des pointes entières, a été effectuée selon une modalité bipolaire plus flexible, non strictement opposée, dont les enlèvements aménageant la convexité distale ne sont pas strictement débités dans le sens opposé des enlèvements proximaux (fig. 13). 
Tabl. III - Répartition des pointes Levallois entières en fonction des technotypes et des modalités de production.

\begin{tabular}{|l|r|r|c|c|c|c|c|r|}
\hline \multirow{2}{*}{$\begin{array}{c}\text { Technotypes } \\
\text { de pointe } \\
\text { Levallois }\end{array}$} & \multicolumn{5}{|c|}{ Modalités de production } & \multicolumn{3}{c|}{ Total } \\
\cline { 2 - 9 } & $\begin{array}{c}\text { Unipolaire } \\
\text { convergent }\end{array}$ & \multicolumn{2}{|c|}{$\begin{array}{c}\text { Bipolaire } \\
\text { opposé }\end{array}$} & \multicolumn{2}{|c|}{ Autres } & \multicolumn{2}{c|}{} \\
\hline Construite & 13 & $15 \%$ & 26 & $30 \%$ & 13 & $15 \%$ & 52 & $60 \%$ \\
\hline $\begin{array}{l}\text { « Classique } \\
\text { (3 coups) }\end{array}$ & 33 & $38 \%$ & - & - & 1 & $1 \%$ & 34 & $39 \%$ \\
\hline Premier ordre & 1 & $1 \%$ & - & - & - & - & 1 & $1 \%$ \\
\hline Total & $\mathbf{4 7}$ & $\mathbf{5 4} \%$ & $\mathbf{2 6}$ & $\mathbf{3 0} \%$ & $\mathbf{1 4}$ & $\mathbf{1 6} \%$ & $\mathbf{8 7}$ & $\mathbf{1 0 0} \%$ \\
\hline
\end{tabular}

La variabilité des modalités de production des pointes construites révèle la diversité dans la préparation des convexités latérales et distales des nucléus à pointe (tabl. III) . Cette flexibilité se retrouve aussi dans le nombre d'enlèvements ayant servi à la préparation de la surface du nucléus qui varie de 4 à 9 négatifs, soit une moyenne de 5,7 négatifs d'enlèvements par pointe (écart-type $=1,5$ ).

\section{Caractéristiques morphométriques des pointes}

La distribution métrique générale des 87 pointes entières paraît hétérogène à première vue (fig. 14). Cette diversité dimensionnelle se retrouve dans l'écart important qui existe entre la plus grande pointe étudiée $(13 \mathrm{~cm}$ x $6 \mathrm{~cm}$ ) et la plus petite $(3 \mathrm{~cm} \mathrm{x} 3,4 \mathrm{~cm})$. Les dimensions moyennes des pointes $(7,4 \mathrm{~cm} \mathrm{x} \mathrm{4,5} \mathrm{cm)} \mathrm{et} \mathrm{les} \mathrm{écarts-types}$ associés (2,23 pour la longueur et 1,24 pour la largeur) ne révèlent pas une hétérogénéité significative de la production générale (fig. 15). Cependant, une distinction nette existe entre les pointes construites et «classiques». Les différences entre les deux technotypes sont bien visibles sur la distribution métrique générale des pointes entières (fig. 14). Les pointes «classiques» sont moins grandes (longueur moyenne : $5,9 \mathrm{~cm}$ ) et moins larges (largeur moyenne: $3,6 \mathrm{~cm}$ ) que les pointes construites (longueur moyenne: $8,4 \mathrm{~cm}$ et largeur moyenne: 4,9 cm). De plus, les écartstypes des dimensions des pointes «classiques» montrent que ces éléments présentent une plus grande hétérogénéité dimensionnelle que les pointes construites. Le rapport d'allongement moyen (longueur/largeur moyenne: 1,7; écart-type: 0,38) atteste d'une élongation assez homogène des produits. L'allongement moyen est quasi identique pour les pointes construites (longueur/largeur moyenne: 1,71; écart-type: 0,27) et «classiques» (longueur/largeur moyenne: 1,66; écart-type: 0,5), mais les écarts-types révèlent une fois de plus une plus grande hétérogénéité des pointes «classiques». Comment expliquer cette plus grande hétérogénéité dimensionnelle pour les pointes «classiques"?

Deux variables peuvent plus particulièrement entrer en jeu et influer sur les dimensions finales des produits: la préparation des convexités distales et latérales, et l'aménagement du plan de frappe. Tout d'abord, les convexités sont mieux et plus facilement contrôlées dans le cadre de la préparation des pointes construites. Cependant, la deuxième variable semble jouer un rôle tout aussi important. En effet, à l'hétérogénéité dimensionnelle des pointes «classiques» se corrèle une variabilité importante des types de talon présents sur ces pointes (fig. 16). À l'inverse, à l'homogénéité dimensionnelle relative des pointes construites est associée seulement deux types de talon: facetté et en chapeau de gendarme. Une relation étroite entre investissement sur la préparation des plans de frappe et régularité dimensionnelle des pointes semble exister. Cette préparation soignée des plans de frappe marque nettement la morphologie proximale du produit, comme il est possible de le constater lors de la superposition des contours d'un échantillon de pointes (fig. 17). La préparation des plans de frappe en chapeau de gendarme est caractéristique et exclusivement réservée à la production des pointes Levallois. Un tel investissement lors de l'aménagement du plan de frappe marque la volonté de limiter les risques d'accidents de taille et de réussir l'extraction à coup sûr. En effet, une préparation en chapeau de gendarme, telle qu'elle se présente sur les pointes de Therdonne, offre l'avantage d'un meilleur contrôle de la percussion, d'un détachement dans l'axe de l'«éperon» du plan de frappe et d'un taux de réussite à l'extraction élevé. Cependant, cet aménagement a pour désavantage de ne pas être économe en matière première.

\section{Caractéristiques morphofonctionnelles des pointes}

Une première approche morphofonctionnelle a été menée sur les 87 pointes entières à partir de l'étude de la variation angulaire des bords et de la partie apicale, de la variation de l'épaisseur et de la superposition des contours des pièces (Gadebois, 2006).

Les mesures des angles des bords des pointes au niveau du talon, au premier quart, à la moitié et au trois quart de la pièce montrent une régularité de ces valeurs (fig. 18). Aucune variation angulaire le long du tranchant de chacune des pointes ne semble exister. Cette régularité angulaire de la partie proximale à la partie distale 


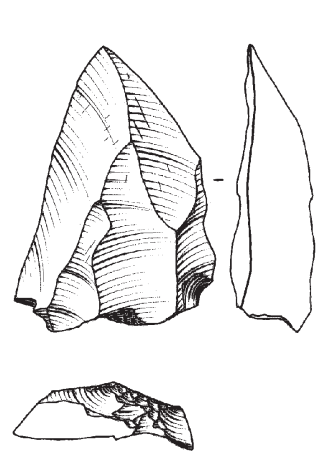

1

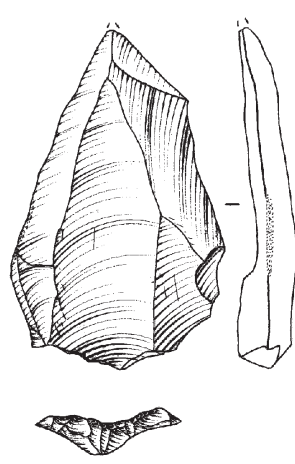

2
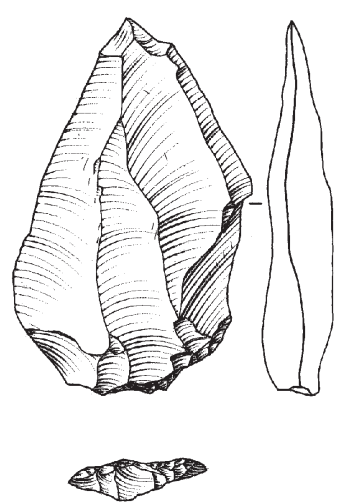

3
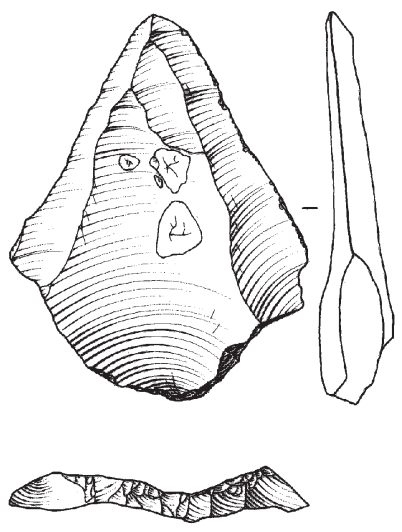

4
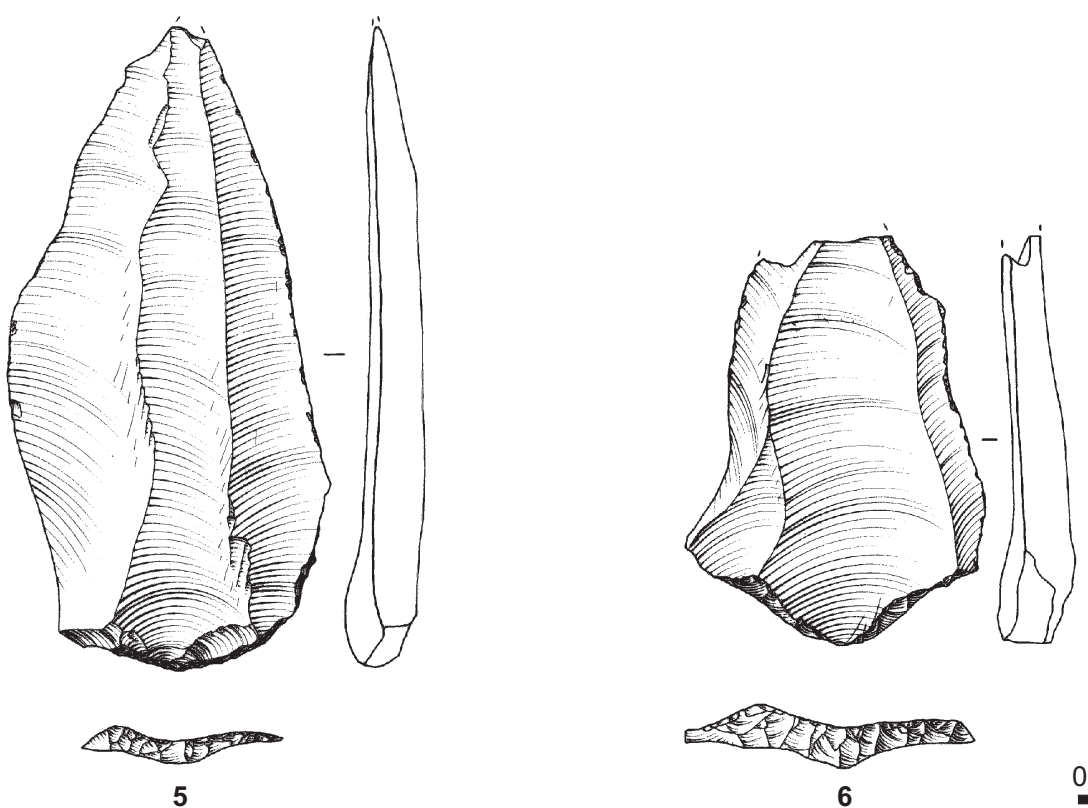

6

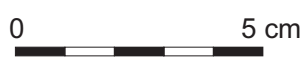

Fig. 11 - Pointes Levallois issues d'une modalité unipolaire convergente (dessin: S. Lancelot, Inrap).

s'exprime sur les deux bords. Aucune différence angulaire significative ne peut être mise en évidence entre le bord gauche (angle moyen: $29,1^{\circ}$ ) et droit (angle moyen : 30, $7^{\circ}$ ) (fig. 18). La valeur moyenne des angles des bords, inférieure à $35^{\circ}$, indique que la majorité des pointes possèdent des caractéristiques morphofonctionnelles adaptées à la coupe rentrante (Wilmsem, 1968; Abril et al., 1981; Siegel, 1985; Lepot, 1993; Soriano, 2000; Soressi, Locht, 2008). Cependant, une partie des pointes présente des valeurs angulaires supérieures à $35^{\circ}$ mais systématiquement inférieures à $65^{\circ}$. Les mêmes travaux que ceux cités ci-dessus proposent un potentiel fonctionnel plus polyvalent de ces pointes, permettant la coupe rentrante et sortante.
La partie apicale est plus affinée que les bords gauche et droit des pointes (fig. 18). Cette faible angulation $\left(20,1^{\circ}\right.$ en moyenne) ajoutée à une épaisseur réduite est la cause de la fragilité importante de la partie apicale de la pièce. Cette fragilité se traduit dans l'assemblage par la présence de 38 pointes fragmentées, soit un peu plus de $30 \%$ de l'ensemble des pointes. Malgré un angle en plan aigu (angle moyen: $31,7^{\circ}$; écart-type: 9,5 ), la faiblesse de la partie apicale, opposée à la régularité des angles des bords, tend à proposer une utilisation privilégiée des bords.

L'épaisseur des pointes diminue de manière régulière avec un affinement progressif vers la partie apicale; en moyenne: $9 \mathrm{~mm}$ au quart, 7,3 $\mathrm{mm}$ à la moitié, $6,3 \mathrm{~mm}$ au 

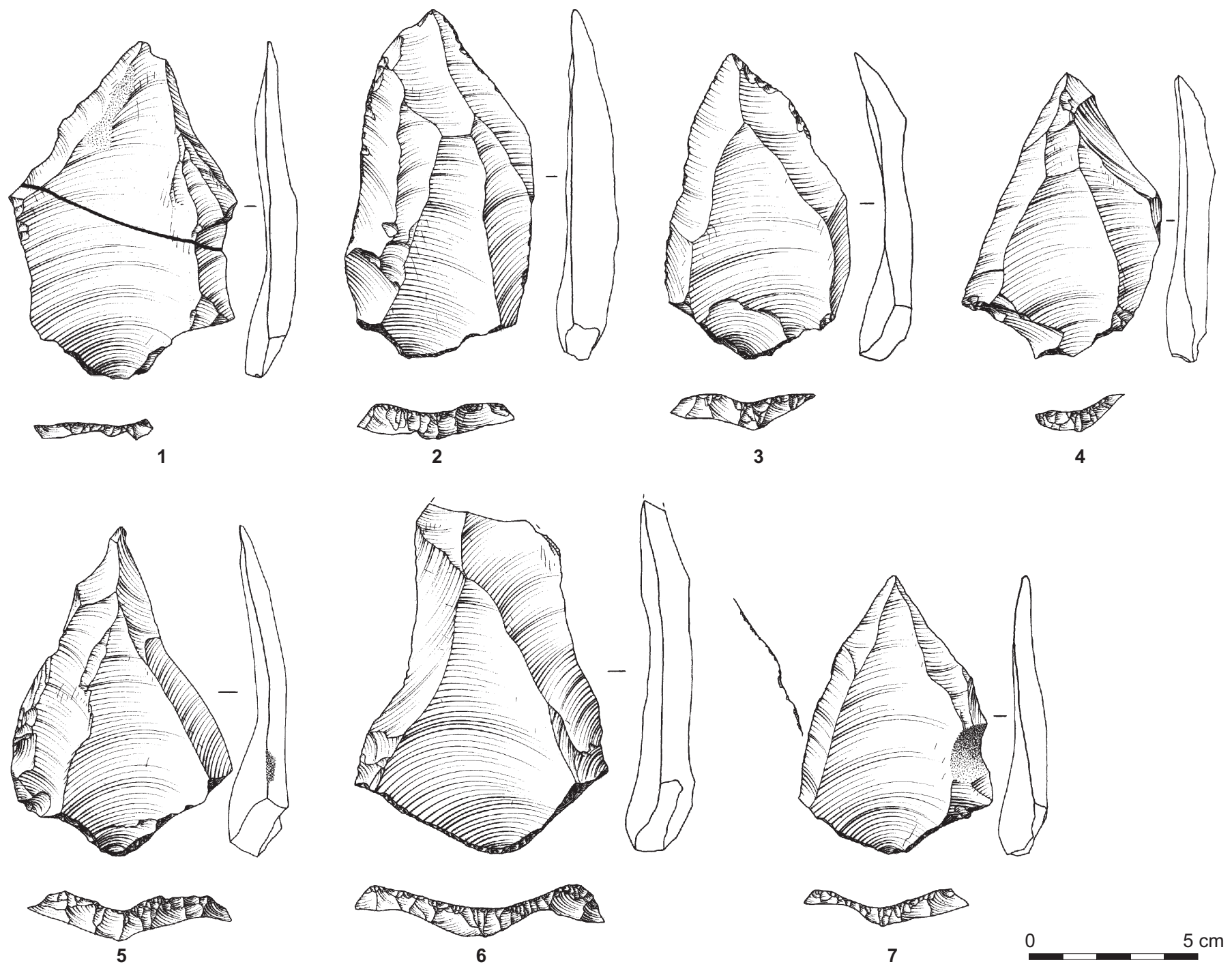

Fig. 12 - Pointes Levallois issues d'une modalité bipolaire opposée (dessin: S. Lancelot, Inrap).

trois quarts (fig. 15). L'épaisseur moyenne de l'ensemble des pointes (épaisseur moyenne: $7,5 \mathrm{~mm}$ ) indique une certaine finesse du produit. Cette finesse n'est pas synonyme de faiblesse dans ce cas puisque les pointes paraissent assez robustes pour permettre, entre autres, des actions de découpe.

Enfin, la superposition des contours des pointes met en évidence une symétrie axiale fortement marquée (fig. 17). Cette symétrie, couplée à l'homogénéité angulaire des bords gauche et droit, montre clairement le potentiel indifférencié des deux bords et une latéralisation fonctionnelle inexistante au moment de la production.

\section{ABSENGE DE NUGLÉUS ET RÉDUCTION EXHAUSTIVE, DEUX PHÉNOMÈNES LIÉS À LA PRODUCTION DES POINTES LEVALLOIS?}

Malgré l'absence de nucléus Levallois à pointe, la présence de ce type de produits est incontestable. Le chiffre de 125 pointes exclut presque d'entrée l'hypothèse d'une importation exclusive de l'ensemble de ces produits sur le gisement depuis un lieu de production éloigné. Il s'agirait sinon pour le Paléolithique moyen de la première mise en évidence d'une séparation nette et récurrente dans une chaîne opératoire entre le lieu de production d'un type 

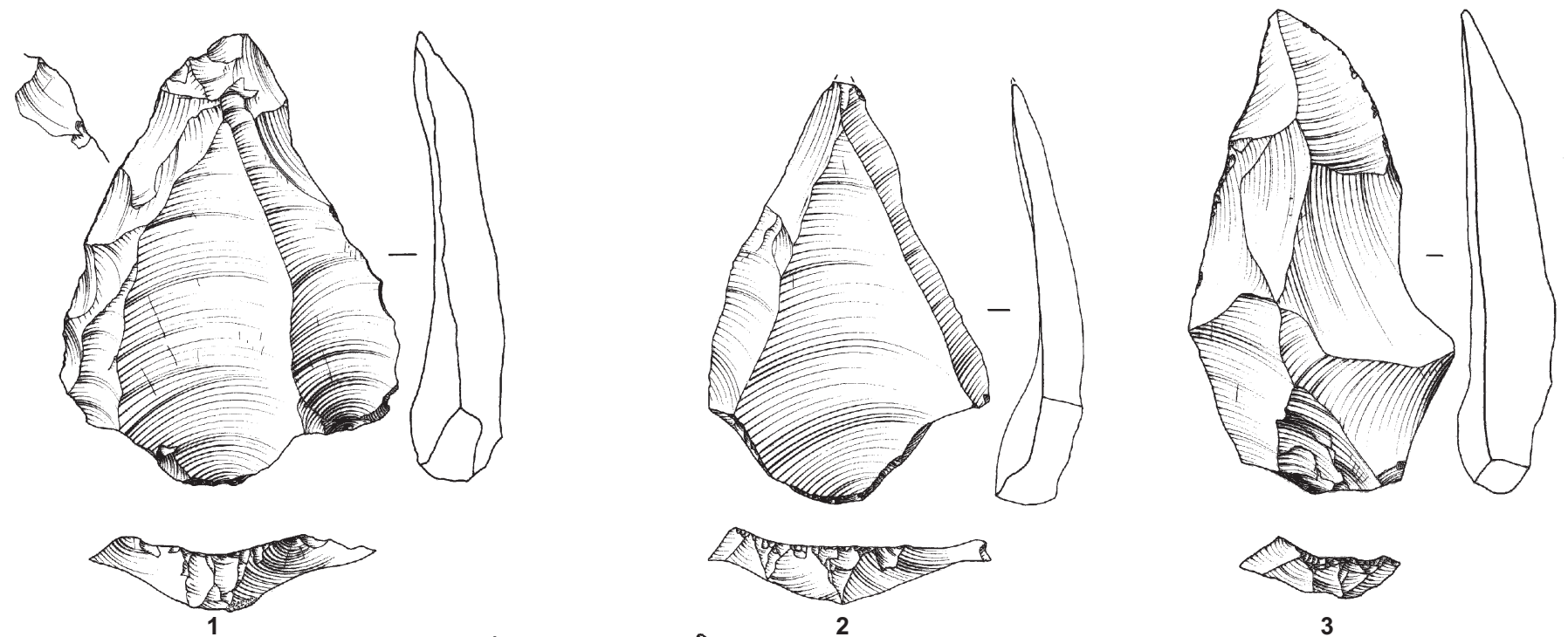

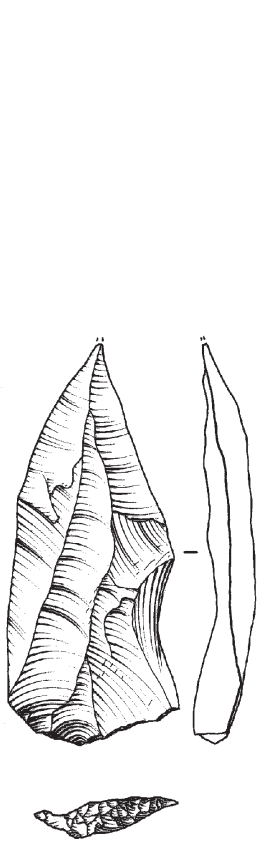

4

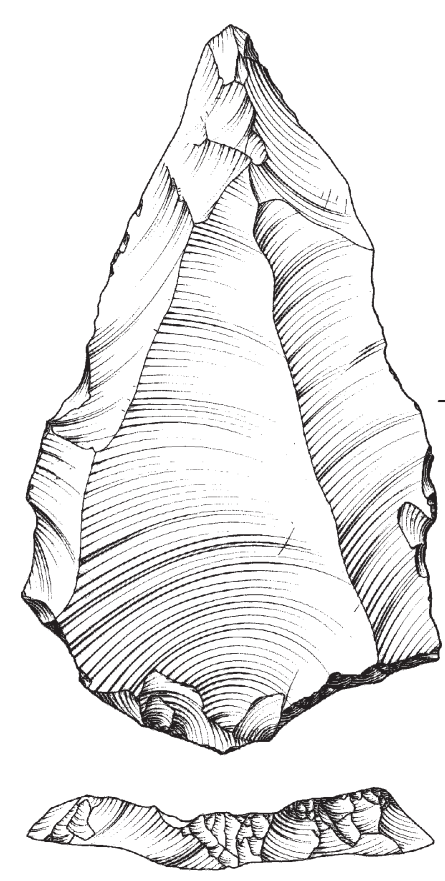

5

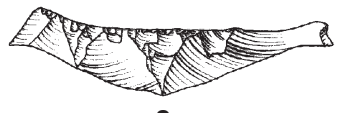

2

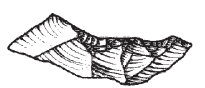

3
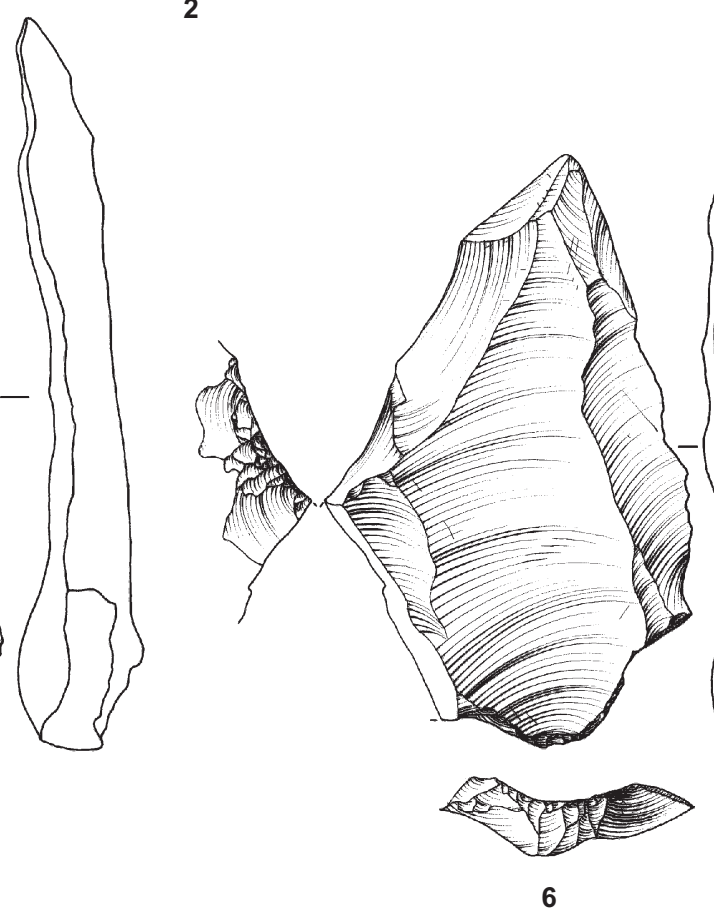

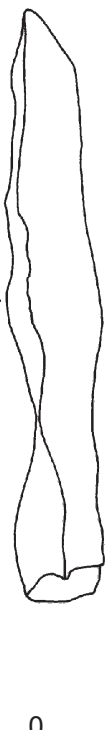

$5 \mathrm{~cm}$

Fig. 13 - Pointes Levallois issues d'autres modalités (dessin: S. Lancelot, Inrap).

d'artefact (la pointe Levallois dans ce cas) et le lieu d'utilisation de ce dernier. Pour tenter d'expliquer ce phénomène, l'absence de nucléus à pointe et la forte présence de pointes Levallois, deux hypothèses de départ avaient été proposées. La première hypothèse "suggèrerait une production en dehors de l'aire de fouille; la seconde induirait un phénomène de réduction des nucléus extrêmement poussé après la production de ces pointes, car les nucléus sont le plus souvent de très petite taille» (Locht et al., 2000, p. 29). Ces deux propositions ont été testées lors d'une étude technologique approfondie (Hérisson, 2007).

Tout d'abord, la première hypothèse est la plus facile à tester grâce aux données numériques. Le décompte général de l'industrie d'un côté révèle un peu plus de 49000 artefacts et 13824 artefacts sans compter les esquilles et les nucléus. De l'autre côté, 69 nucléus ont été retrouvés. Le 


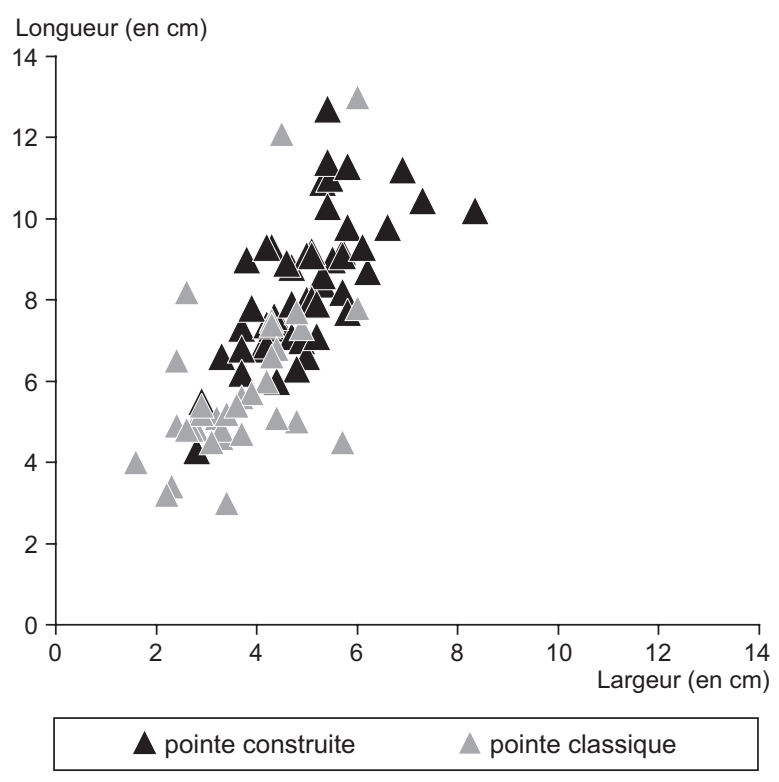

Fig. 14 - Distribution des pointes Levallois construites et «classiques» en fonction de leur longueur et de leur largeur.

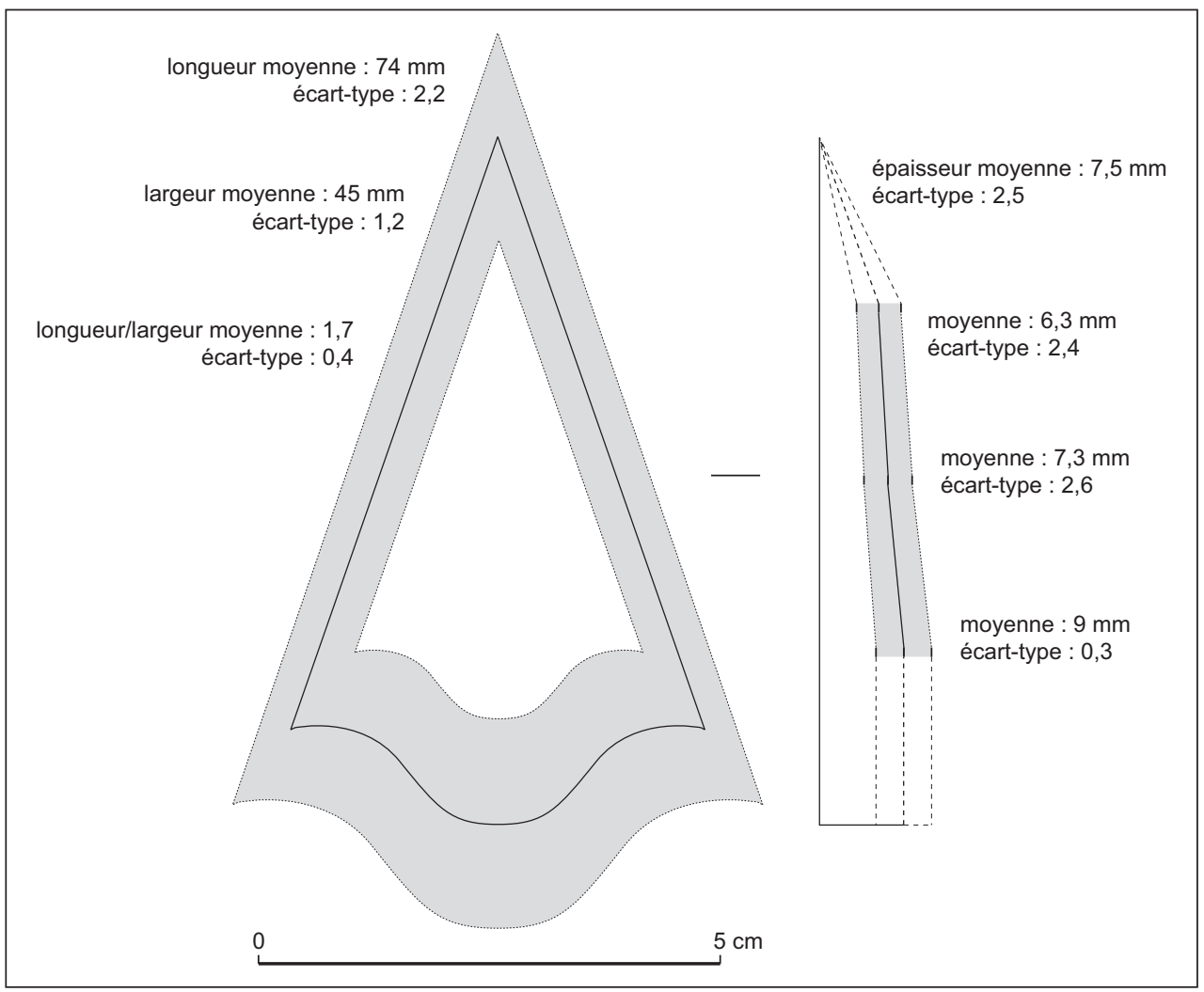

Fig. 15 - Schémas représentant les dimensions moyennes des pointes (trait noir continu) et l'écart-type associé (zone grisée) en longueur et en largeur ainsi qu'en épaisseur à l'échelle 1:1 (DAO: D. Hérisson, CNRS). 


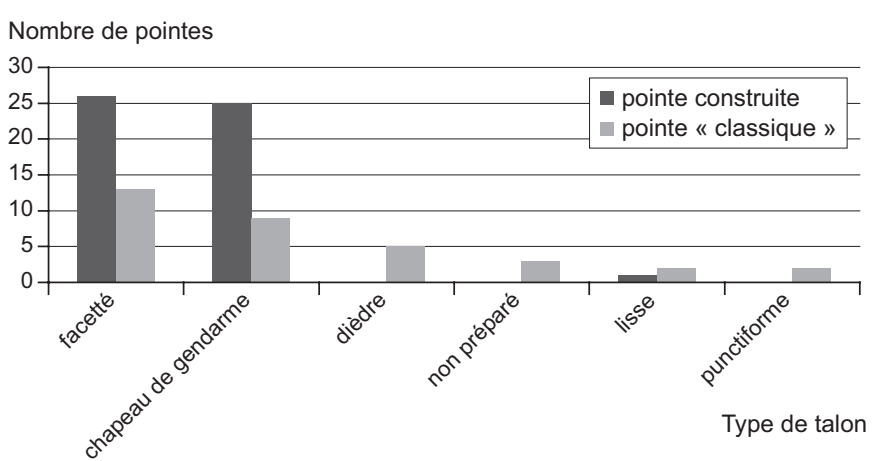

Fig. 16 - Distribution des pointes construites et «classiques» en fonction du type de leur talon.

simple rapport du nombre total d'artefacts sans les esquilles sur le nombre de nucléus donne un résultat de 200 produits par nucléus.

Le raisonnement peut être poussé plus loin. Il est possible d'évaluer la productivité des nucléus faiblement prédéterminés et laminaires de l'assemblage. Il suffit ensuite de soustraire cette production du nombre d'artefacts recueillis afin d'estimer la productivité des nucléus Levallois et discoïdes nécessaire à l'obtention de l'ensemble des pièces recueillies de la série et de vérifier si cette productivité hypothétique est recevable.

D’après le décompte des négatifs, les nucléus faiblement prédéterminés ont produit en moyenne 6 éclats par nucléus en une seule et unique séquence de débitage. Les nucléus faiblement prédéterminés ont donc produit, à quelques dizaines d'éclats près, 204 éclats (tabl. IV). En ce qui concerne le débitage laminaire, un nucléus a produit 9 lames et les deux autres nucléus ont produit 21 artefacts par séquence de débitage. En prenant une marge importante, considérons qu'il y ait eu cinq séquences de débitage. Les nucléus laminaires auraient produit environ 219 artefacts. En soustrayant dans un premier temps les éclats produits par les nucléus faiblement prédéterminés et laminaires au nombre total d'artefacts sans les esquilles, le total obtenu est de 13409 artefacts (tabl. IV).

D’autre part, les nucléus discoïdes ont produit en moyenne 16 éclats par nucléus, d'où une production totale de 112 éclats par séquence de débitage pour tous les nucléus discoïdes. En ce qui concerne les nucléus Levallois, 9 éclats ont été produits en moyenne par nucléus. En prenant à nouveau une marge conséquente, en considérant que les nucléus Levallois ont produit trois fois plus de produits au total que sur leur seule surface de débitage, la production d'éclats s'élèverait à 675 éclats par séquence de débitage pour tous les nucléus Levallois.

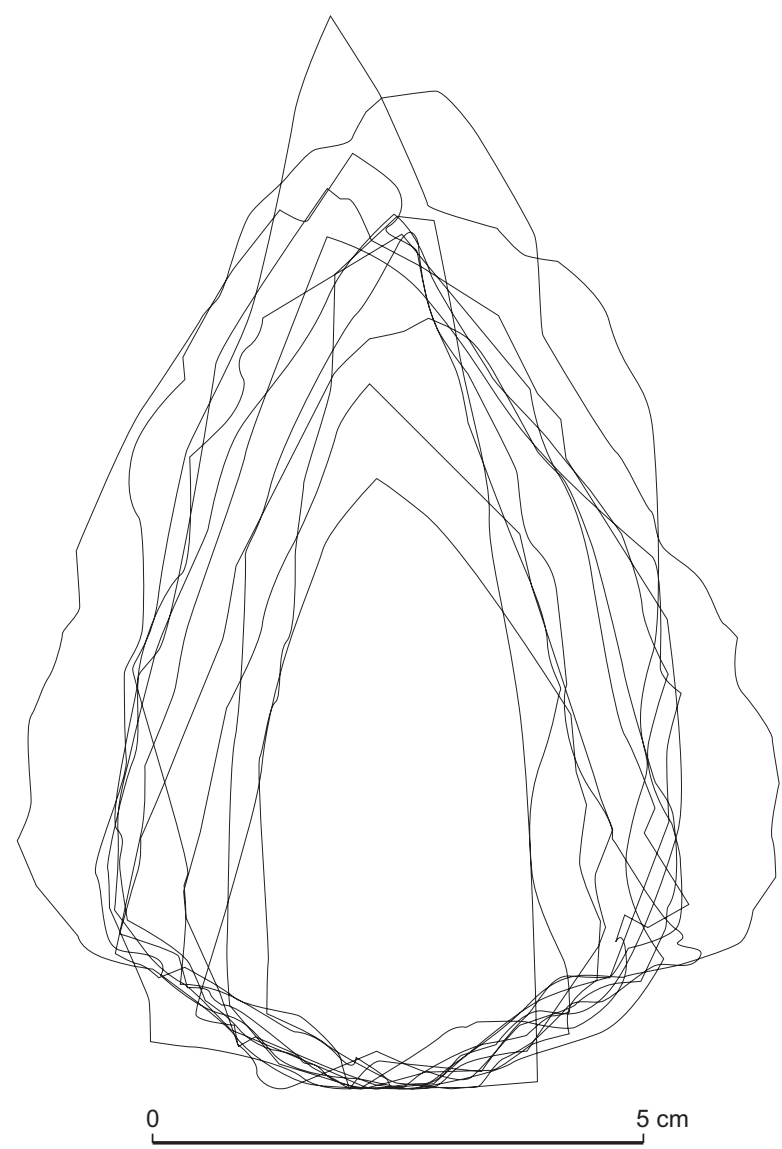

Fig. 17 - Superposition des contours d'un échantillon de douze pointes Levallois (DAO: G. Gadebois).

Ainsi, les nucléus Levallois et discoïdes ont pu produire au maximum (vu la marge importante prise pour la démonstration) 787 éclats par séquence de débitage. Il ne reste donc plus qu'à diviser le nombre restant d'artefacts n'ayant pas encore de nucléus par le nombre d'artefacts produits par séquence de débitage par les nucléus Levallois et discoïdes. Ainsi, le nombre hypothétique de séquences de débitage nécessaire à la production de tous les artefacts restants du site (esquilles exclues) est le suivant: 13409/787 = 17 séquences nécessaires (tabl. IV). En d'autres termes, il aurait fallu plus de seize séquences de débitage par nucléus Levallois et discoïdes pour produire le nombre d'artefacts restant (c'est-à-dire après soustraction des produits laminaires et faiblement prédéterminés). Cela représente en termes plus concrets plus de 459 éclats par nucléus Levallois et 272 éclats par nucléus discoïdes (tabl. IV). Une telle productivité est difficilement concevable pour les blocs de matière première de grandes dimensions et elle devient inconcevable vu la taille réduite des blocs exploités à 


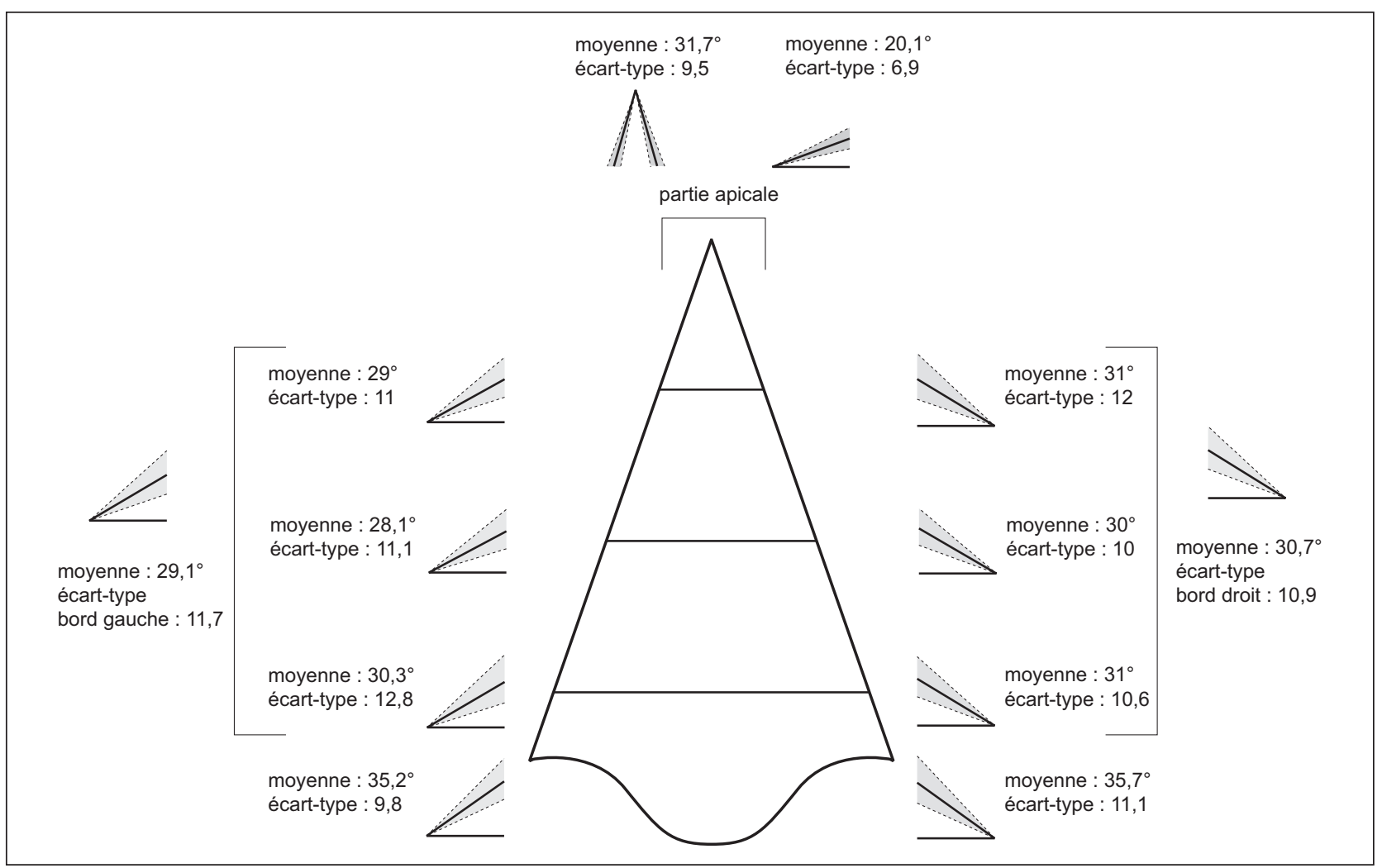

Fig. 18 - Valeurs angulaires moyennes et écarts-types associés des bords et de la partie apicale des pointes Levallois (DAO: D. Hérisson, CNRS).

Tabl. IV - Estimations des productions d'artefacts en fonction des différentes catégories de nucléus.

\begin{tabular}{|c|c|c|c|c|}
\hline $\begin{array}{l}\text { Nombre } \\
\text { de nucléus }\end{array}$ & $\begin{array}{c}\text { Estimation } \\
\text { du nombre } \\
\text { d'éclats / séquence / nucléus }\end{array}$ & $\begin{array}{c}\text { Estimation } \\
\text { du nombre } \\
\text { de séquences / nucléus }\end{array}$ & $\begin{array}{c}\text { Estimation du nombre } \\
\text { d'éclats produits par } \\
\text { l'ensemble d'une catégorie } \\
\text { de nucléus }\end{array}$ & $\begin{array}{c}\text { Nombre total d'artefacts - } \\
\text { nombre d'éclats produits } \\
\text { estimés }\end{array}$ \\
\hline $\begin{array}{c}34 \text { nucléus faiblement } \\
\text { prédéterminés }\end{array}$ & 6 & 1 & $34 \times 6 \times 1=204$ & $13832-204=13628$ \\
\hline 3 nucléus laminaires & $9(n=1)$ et $21(n=2)$ & $1(n=1)$ et $5(n=2)$ & $(1 \times 9 \times 1)+(2 \times 21 \times 5)=\mathbf{2 1 9}$ & $13628-219=13409$ \\
\hline $\begin{array}{l}\text { Nombre } \\
\text { de nucléus }\end{array}$ & $\begin{array}{l}\text { Estimation du nombre } \\
\text { d'éclats / séquence / nucléus }\end{array}$ & $\begin{array}{l}\text { Estimation du nombre } \\
\text { d'éclats produits par } \\
\text { l'ensemble d'une catégorie } \\
\text { de nucléus par séquence }\end{array}$ & $\begin{array}{l}\text { Nombre de séquences } \\
\text { nécessaires à la } \\
\text { production de l'ensemble } \\
\text { des artefacts de la série }\end{array}$ & $\begin{array}{l}\text { Nombre d'éclats par } \\
\text { nucléus nécessaires à la } \\
\text { production de l'ensemble } \\
\text { des artefacts de la série }\end{array}$ \\
\hline 7 nucléus discoïdes & 16 & $16 \times 7=112$ & \multirow{2}{*}{$13409 /(675+112)=17$} & $17 \times 16=272$ \\
\hline 25 nucléus Levallois & 9 & $9 \times 25 \times 3=675$ & & $17 \times 9 \times 3=459$ \\
\hline
\end{tabular}

Therdonne (15-20 cm maximum) et donc du volume de ces blocs qui ne permet d'envisager, dans le meilleur des cas, moins de dix séquences de débitage par nucléus.

D'après ces observations, d'autres nucléus non présents dans l'aire de fouille ont très certainement produit une partie non négligeable des artefacts recueillis. Ainsi, la première hypothèse d'une production en dehors de l'aire de fouille des pointes Levallois, ainsi que d'autres artefacts, est recevable.

La seconde hypothèse se retrouve-t-elle alors invalidée d'office ? Dans un premier temps, il a été confirmé qu'aucun éclat Levallois de second ordre ne portait de négatif d'enlèvement de pointe (Boëda, 1994). Un test systématique de remontage pointe sur pointe a aussi été 


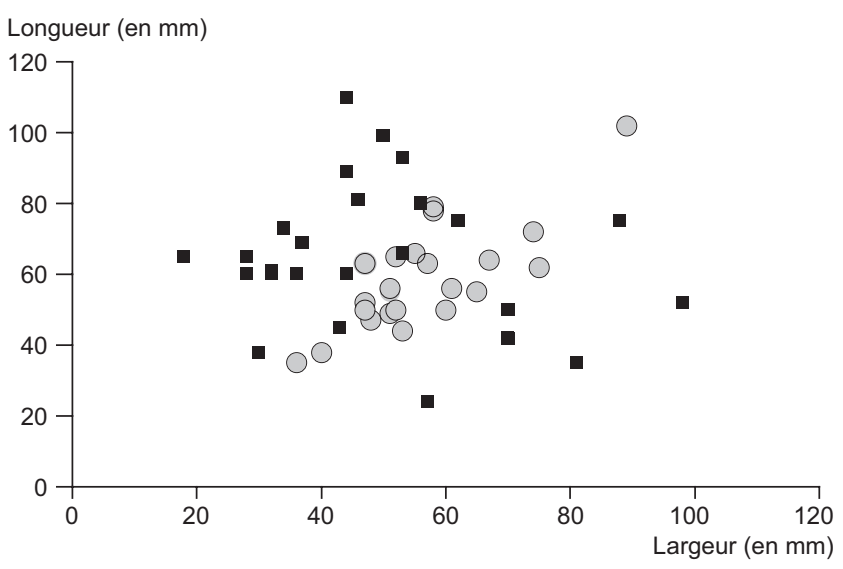

nucléus Levallois éclats débordants

Fig. 19 - Distribution des nucléus Levallois et des éclats débordants en fonction de leur longueur et de leur largeur.

tenté mais n’a donné aucun résultat. Ensuite, une recherche méthodique des éclats dits «techniques» pouvant appartenir à un débitage Levallois et démontrant une réduction a été effectuée. Ainsi, 38 éléments ont été isolés: les 12 éclats débordants droits entiers et les 20 éclats débordants gauches entiers sont plus longs que les nucléus Levallois. Les dimensions des éclats débordants et des nucléus Levallois mettent bien en évidence un phénomène de réduction important (fig. 19). En effet, le plus grand éclat débordant mesure $110 \mathrm{~mm}$ de long pour $44 \mathrm{~mm}$ de large et $26 \mathrm{~mm}$ d'épaisseur tandis que le plus petit mesure $38 \mathrm{~mm}$ x $30 \mathrm{~mm}$ x $4 \mathrm{~mm}$. D’autres éclats débordants plus petits ont été retrouvés mais n'ont pas été intégrés pour le moment, car il est difficile d'affirmer avec certitude sans remontage qu'ils appartiennent bien à une chaîne opératoire Levallois. Ce phénomène de réduction est aussi confirmé par plusieurs remontages. Sur certains d'entre eux, plusieurs séquences successives de débitage avec préparation et recul du plan de frappe au fil du débitage peuvent être observées.

Notons aussi la présence, au sein d'un remontage, d'un éclat de ravivage d'importantes dimensions qui permet le dégagement d'un nouveau plan de frappe et réduit en même temps la longueur du nucléus de près de $1 \mathrm{~cm}$. Pour l'instant, 4 autres éclats de ravivage de plan de frappe ont été retrouvés et caractérisés comme tels. Grâce à l'un de ces artefacts, un certain nombre d'éléments de réponse fondamentaux concernant la production des pointes Levallois est apparu. En effet, sur la face supérieure de cet éclat de ravivage se dessine le négatif d'enlèvement d'une pointe Levallois (fig. 20). La présence d'un tel élément indique clairement qu'au moins une partie de la chaîne opératoire à pointes a été effectuée sur place. De plus, elle confirme que les nucléus Levallois à pointe ont subi une réduction avec plusieurs séquences de débitage successives. Les points de percussion présents sur le chapeau de gendarme qu'a ôté l'éclat de ravivage peuvent indiquer la volonté d'extraire successivement deux pointes Levallois sans ravivage du plan de frappe (fig. 20). Cette hypothèse n'est bien sûr valable que si ces tentatives sont postérieures à l'extraction de la pointe. Toutefois, la première solution reste la plus vraisemblable. Le tailleur aurait donc choisi de radicalement modifier la morphologie de son nucléus après l'échec d'extraction d'autres pointes Levallois (fig. 20). Ce type d'enlèvement de ravivage entraîne une rupture dans la chaîne opératoire puisqu'il implique une nouvelle préparation conséquente du nucléus, synonyme de perte importante de volume. Cette rupture dans la chaîne opératoire se traduit-elle aussi par un changement de modalité d'exploitation du nucléus, désormais trop réduit pour produire de grandes pointes Levallois, ou marque-t-elle simplement le passage d'une production de pointes Levallois de grandes dimensions à des pointes Levallois de dimensions plus réduites ? À l'heure actuelle, sans remontage le prouvant, il reste difficile de répondre à cette question. Les deux solutions ont pu coexister. Certains nucléus ont très bien pu produire exclusivement des pointes Levallois et sont abandonnés comme tels lorsqu'ils sont trop réduits pour produire des pointes; dans ce cas, les nucléus de ce type se trouveraient en dehors de l'aire de fouille. D'autres nucléus ont pu produire des pointes Levallois de grandes dimensions dans les premières séquences de débitage, puis ont été exploités selon d'autres modalités Levallois permettant l'extraction d'éclats Levallois, lorsque leur taille ne permettait plus la production de grandes pointes. Dans ce cas, les nucléus retrouvés dans l'aire de fouille et classés comme nucléus Levallois récurrents peuvent avoir produit des pointes Levallois avant la mise en place des modalités de débitage des dernières séquences qui ont permis de les caractériser comme nucléus Levallois récurrents.

Une autre pièce apporte aussi une part de réponses et de questions: il s'agit d'une pointe Levallois outrepassée (fig. 21). Avec les autres petites pointes Levallois, ses dimensions réduites confirment qu'à côté d'une production de pointes Levallois de grandes dimensions existe une production de pointes Levallois de petites dimensions répondant probablement à un objectif différent. La pointe Levallois outrepassée montre bien une préparation envahissante. Celle-ci est également perceptible sur l'éclat de ravivage 

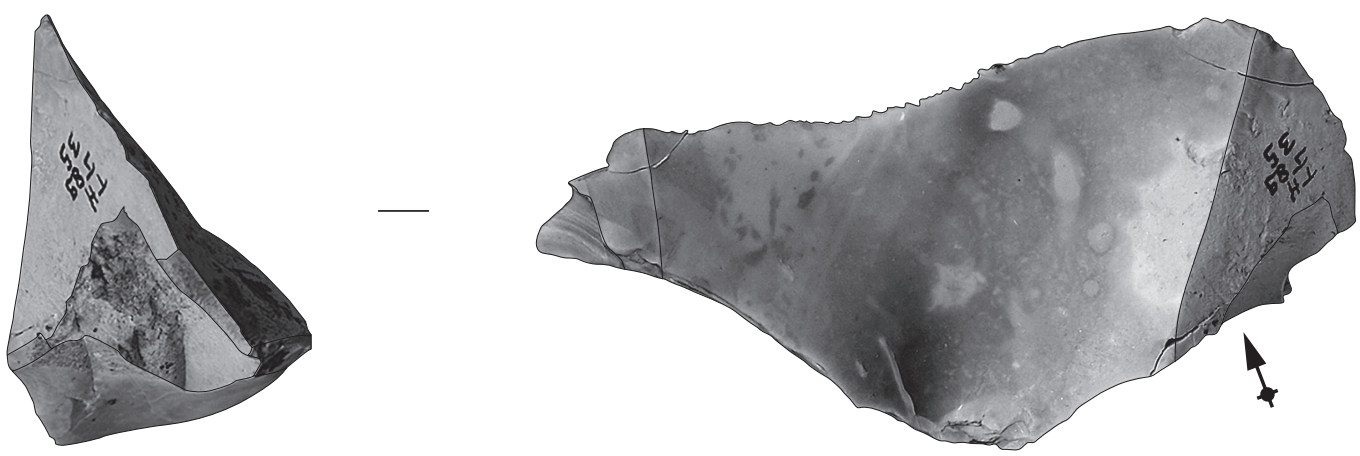

1
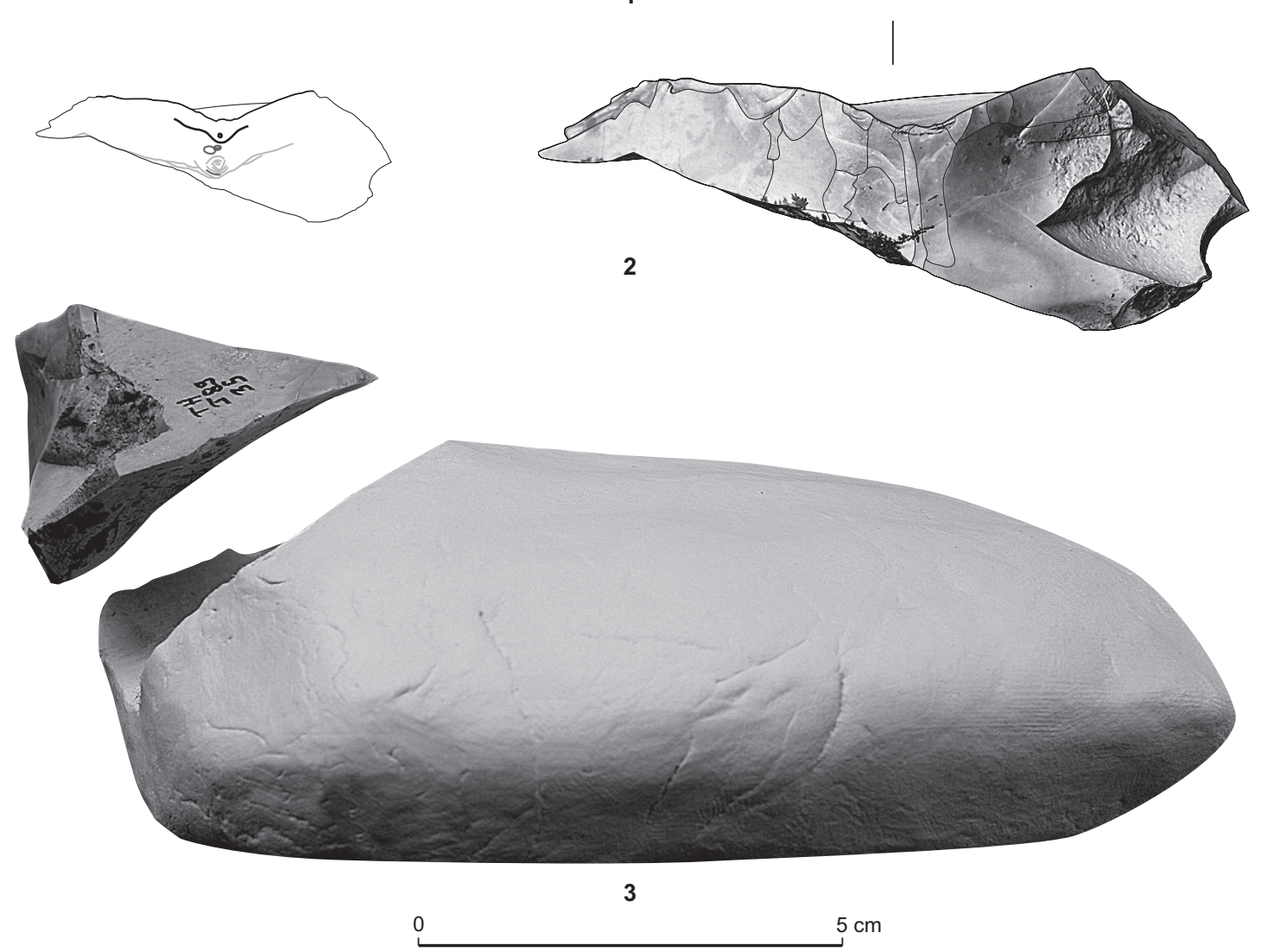

Fig. 20 - 1, éclat de ravivage de plan de frappe d'un nucléus Levallois à pointe; 2, stigmates de percussion visibles sur le plan de frappe en chapeau de gendarme à l'échelle 1:2; 3, vue éclatée de profil de l'éclat de ravivage de plan de frappe et de son nucléus reconstitué (cliché et DAO: D. Hérisson, CNRS).

(fig. 20). Cet envahissement de la face supérieure du nucléus par les pointes implique une repréparation complète de la surface de production et un ravivage du plan de frappe après l'extraction d'une ou de plusieurs pointes successives, impliquant une réduction des nucléus.

L'élément le plus important qu'apporte cette pointe Levallois est la confirmation d'une production des pointes Levallois in situ. En effet, cette pointe Levallois ratée involontairement, à l'utilisation compromise, sans utilité fonctionnelle évidente, ne peut normalement pas être un élément importé sur le site. De même, la localisation des deux grands indices de production sur place (l'éclat de ravivage de nucléus à pointe et la pointe Levallois outrepassée) aux limites de l'extension de l'aire de fouille laisse subodorer la présence d'éléments appartenant à la châne opératoire à pointes, y compris d'éventuels nucléus à pointe, 

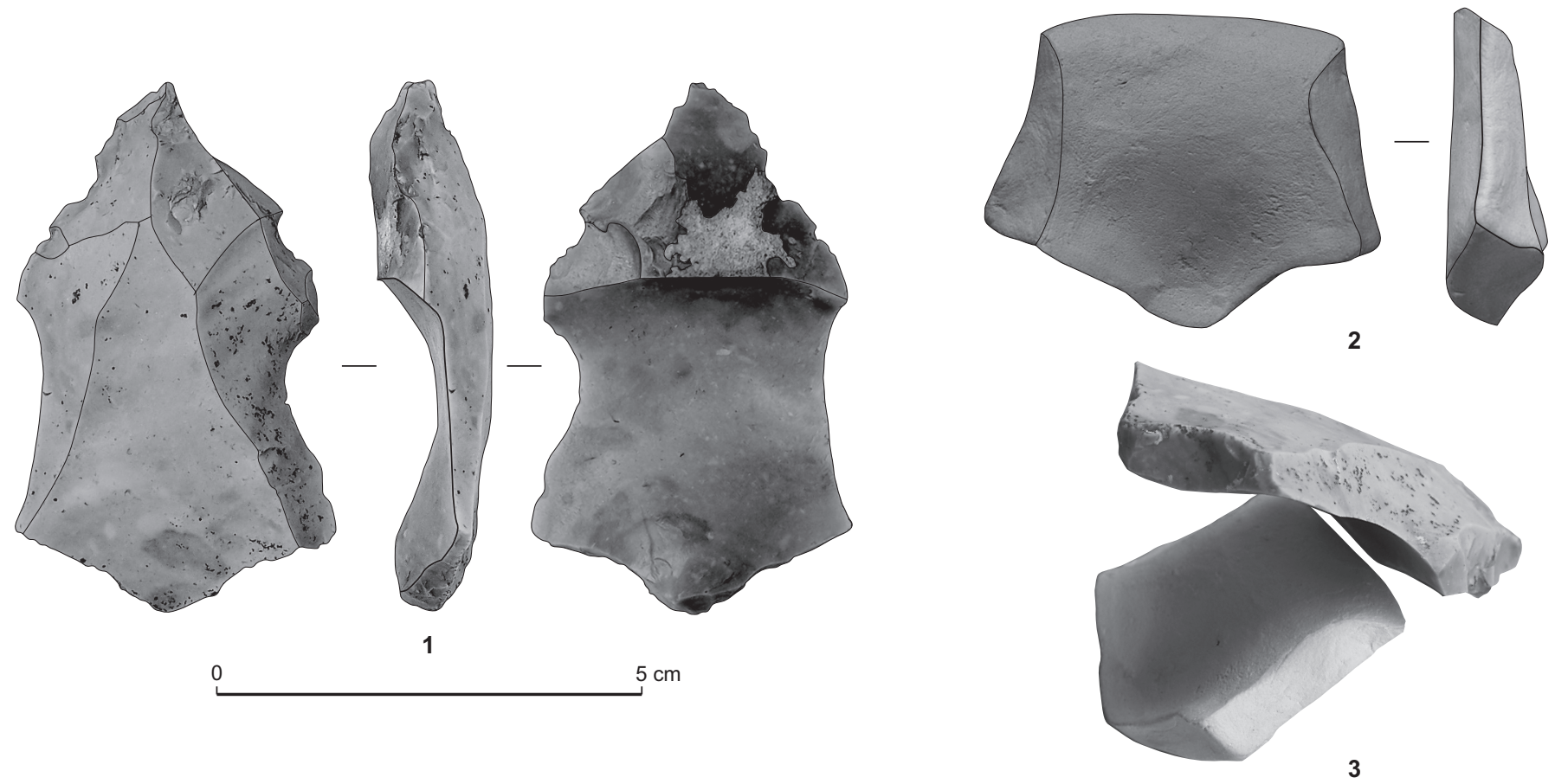

Fig. 21 - 1, pointe Levallois outrepassée; 2, nucléus reconstitué après l'extraction de la pointe outrepassée (1); 3, vue éclatée de la pointe outrepassée et de son nucléus reconstitué (cliché et DAO: D. Hérisson, CNRS).

en bordure occidentale de la zone de fouille, c'est-à-dire dans le prolongement immédiat du niveau d'occupation N3. Enfin, la présence dans la série de plusieurs pointes ayant rebroussé et ne possédant aucune des propriétés morphofonctionnelles recherchées prouve indubitablement qu'au moins une partie des pointes ont été produites in situ (fig. 22).

En résumé, la validité des deux hypothèses avancées a été testée pour expliquer l'absence des nucléus Levallois à pointe dans la série malgré la présence de très nombreuses pointes Levallois de grandes dimensions. La première «suggèrerait une production en dehors de l'aire de fouille " (Locht et al., 2000, p. 29). Il est désormais indiscutable que l'intégralité des artefacts extraits de la zone de fouille n'a pu être produite par les seuls nucléus retrouvés. Cependant, l'éclat de ravivage de plan de frappe de nucléus à pointe et la pointe Levallois outrepassée prouvent à la fois une production in situ des pointes et une localisation à proximité immédiate tout à fait envisageable des nucléus Levallois à pointe. Tous ces éléments ainsi que la présence de pointes rebroussées indiquent que la production des pointes Levallois a été effectuée in situ et en partie à proximité immédiate, au-delà de la limite artificielle contemporaine que représente l'extension de la zone de fouille.

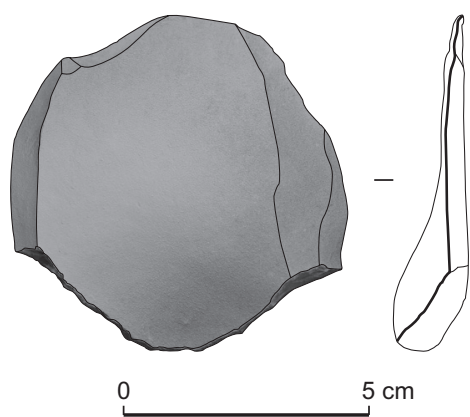

Fig. 22 - Pointe Levallois rebroussée (cliché et DAO: D. Hérisson, CNRS).

La seconde hypothèse «induirait un phénomène de réduction des nucléus extrêmement poussé après la production de ces pointes, car les nucléus sont le plus souvent de très petite taille» (Locht et al., 2000, p. 29). L'existence d'un phénomène de réduction très poussée a bien été mise en évidence pour les chaînes opératoires Levallois à éclats et à pointes par l'étude technologique des éclats débordants, des éclats de ravivage de plan de frappe de nucléus Levallois, de la pointe Levallois outrepassée, de l'éclat de ravivage de plan de frappe de nucléus Levallois à pointe et des nucléus Levallois récurrents. 
La réalité archéologique confirme la validité des deux hypothèses, montrant que la combinaison de ces dernières est la cause de l'absence de nucléus Levallois à pointe dans l'aire de fouille.

\section{PLACE DU GISEMENT DE THERDONNE DANS LA FRANCE SEPTENTRIONALE ET L'EUROPE DU NORD-OUEST}

Dans le cadre de la France septentrionale, le niveau N3 de Therdonne se présente comme l'un des rares témoignages d'occupation humaine au calage chronostratigraphique fiable pour le Saalien. Attribuable à la fin du stade isotopique 7, l'occupation peut être corrélée aux gisements de Montières-les-Amiens à Amiens - carrière Boutmy-Muchembled (Tuffreau, 1983; Antoine, 1990; Laurent, 1993), Tourville-la-Rivière en Seine-Maritime (Guilbaud, Carpentier, 1995; Antoine et al., 1998) ainsi qu'aux niveaux B du Pucheuil à Saint-Saëns (Delagnes, Ropars dir., 1996) et D et D1 de Biache-Saint-Vaast dans le Pas-de-Calais (Tuffreau, Sommé dir., 1989). Le niveau N3 de Therdonne possède des caractéristiques communes aux gisements attribués à la phase ancienne du Paléolithique moyen du nord de la France. La coexistence de plusieurs chaînes opératoires est un fait récurrent durant le Saalien et atteste de la contemporanéité des différentes chaînes. Concernant le concept Levallois, il est parfaitement mâ̂trisé dès le début du Saalien et a servi à la production d'artefacts sur tous les gisements saaliens fouillés du nord de la France. Cette parfaite maîtrise de la méthode Levallois s'exprime dans la production des pointes à Therdonne. Seule l'occupation N3 de Therdonne et le niveau B du Pucheuil ont livré une chaîne opératoire à pointes Levallois pour la phase ancienne du Paléolithique moyen de la France septentrionale. Cette chaîne opératoire est d'autant plus caractéristique qu'elle apparaît comme le principal objectif de production du niveau N3. Les pointes Levallois de Therdonne et du Pucheuil affichent les mêmes caractères techno-morphofonctionnels: modalité Levallois unipolaire convergente dominante, préparation soignée des plans de frappe (facetté ou en chapeau de gendarme) et morphométrie des pointes. Cependant, un phénomène distingue notamment les deux gisements: les nucléus Levallois à pointe. En effet, contrairement à Therdonne, où l'absence de nucléus Levallois à pointe est remarquable devant l'abondance des pointes, A. Delagnes a émis l'hypothèse qu' «un certain nombre de pointes Levallois aient été exportées soit hors du site, soit hors de leur zone de production » (Delagnes,
Ropars dir., 1996, p. 91). Malgré un point de divergence, le gisement du Pucheuil reste le point de comparaison le plus proche géographiquement comme technologiquement du gisement de Therdonne. La présence du débitage laminaire est également un des faits remarquables. Elle permet de confirmer l'existence d'une telle production en France septentrionale dès le Saalien après la première occurrence découverte à Saint-Valéry-sur-Somme et attribuée au stade isotopique 8 (Heinzelin, Haesaerts, 1983). À Therdonne, contrairement aux niveaux G-H de Gouzeaucourt dans le Nord (Tuffreau, Bouchet, 1985; Soriano, 2000, p. 279-354) ou des B et A-C du Pucheuil (Delagnes, Ropars dir., 1996), aucun biface directement associé au niveau d'occupation n'a été retrouvé. Les 9 pièces bifaciales ont été mises au jour à la base des sables éolisés et sont antérieures à la principale occupation N3. D'un point de vue taphonomique, les excellentes conditions de préservation de la répartition spatiale des vestiges n'a d'équivalent pour le Saalien du nord de la France que certains niveaux de Biache-Saint-Vaast.

Les occupations corrélées au Saalien et bien calées chronologiquement pour le reste de l'Europe du NordOuest sont rares. En effet, peu de gisements ont pu être datés avec précision de l'une des phases saaliennes. Cependant, des gisements comme Ranville, Calvados (Cliquet dir., 2009), la Cotte de Saint Brelade, Jersey (Callow, 1986; Callow, Cornford dir., 1986; Soriano, 2000, p. 213-277), la grotte de Pontnewydd, Pays de Galles (Green et al., 1989) ou Ariendorf, Allemagne (Turner et al., 1997), se rapprochent à quelques milliers d'années près de l'occupation N3. Le concept Levallois est attesté dans la quasi-intégralité des gisements corrélables de l'Europe du Nord-Ouest: Mesvin IV, Belgique (Cahen, Michel, 1986; Soriano, 2000, p. 137-211), Le Rissori unité IV, Belgique (Adam, Tuffreau, 1973; Adam, 1991), MaastrichtBelvédère C et G (Roebroeks, 1988; De Loecker, 2004), La Cotte de Saint Brelade (Callow, 1986; Callow, Cornford dir., 1986; Soriano, 2000, p. 213-277), Achenheim sol 74 (Sainty, Thévenin, 1978; Lautridou et al., 1985; Junkmanns, 1995), Pontnewydd (Green et al., 1989), Rheindahlen (Thieme et al., 1981) et Piégu à Pléneuf-Val-André dans les Côtes-du-Nord (Monnier, 1985). Il est donc présent durant tout le Saalien en Europe du Nord-Ouest. Le gisement présentant le plus de points communs du point de vue de l'industrie lithique avec Therdonne est situé en Angleterre. L'assemblage de Creffield Road a jusqu'à présent été corrélé à la fin du stade isotopique 8 ou au début du stade isotopique 7 (Ashton et al., 2003; Scott, 2006, p. 82-125). La série a révélé de très grandes pointes Levallois issues 
de nucléus à deux plans de frappe opposés, et aux talons préparés en chapeau de gendarme (Locht et al., 2000, p. 57). Les nucléus de l'assemblage associés à ces pointes sont de très petites dimensions et certains présentent clairement des négatifs d'enlèvements unipolaires convergents et de pointes. Ce phénomène de réduction poussée est, entre autres, perceptible dans les assemblages de Creffield Road, Le Pucheuil, Biache-Saint-Vaast ou Therdonne. Il apparaît comme l'une des rares différences qui existent entre les gisements saaliens et les gisements plus récents du Weichsélien. Comme le confirme l'industrie lithique de l'occupation N3 de Therdonne, tous les systèmes de production reconnus pour le Paléolithique moyen du nord de la France sont maîtrisés dès le début de la période, c'està-dire dès le début du Saalien (Hérisson et al., à paraître; Hérisson, en cours).

$$
\text { * }
$$

L'étude géologique du gisement de Therdonne a mis en évidence la succession de deux cycles chronoclimatiques de type glaciaire-interglaciaire. L'occupation N3, contenue dans un sable humifère, a été attribuée à la fin du stade isotopique 7, aux alentours de 180000 BP. Cette attribution chronostratigraphique a été confirmée par les datations obtenues par TL sur silex chauffés à $178 \pm 11$ ka BP. La prise en compte des différents facteurs taphonomiques laisse supposer une excellente conservation de la répartition des artefacts au sol qui permettra une analyse spatiale de l'occupation. L'étude préliminaire de l'industrie lithique a mis en avant les principales caractéristiques du niveau N3.

Les Préhistoriques ont privilégié des matières premières lithiques locales $(<1 \mathrm{~km})$ et principalement de bonne qualité, en particulier le silex tertiaire à cortex verdi du Thanétien. Une étude plus poussée devrait permettre de mieux quantifier la part et caractériser la provenance des rares matières exogènes importées. Trois chaînes opératoires coexistent. Une première, anecdotique, a pour objectif la production de lames. Les éclats, produits selon des schémas Levallois, discoïde ou faiblement prédéterminé, se présentent comme l'objectif d'une des deux principales chaînes opératoires de l'occupation. La dernière chaîne a permis la production de nombreuses pointes Levallois. Les trois chaînes opératoires sont complètes (mise à part l'absence des nucléus Levallois à pointe) et ont donc été effectuées sur place. Les interactions entre chaîne opératoire à éclats et à pointes restent à caractériser en menant une étude plus approfondie des différentes stratégies de réduction mises en ouvre par les Paléolithiques (Hérisson, en cours).

Les pointes Levallois sont incontestablement un marqueur fort de l'industrie du niveau N3. Les premières analyses menées montrent que les pointes construites se différencient des pointes «classiques» par leurs plus grandes dimensions. Aucun autre gisement de l'Europe occidentale n'atteste de l'utilisation d'une chaîne opératoire Levallois à pointes dominant les autres objectifs de production et ayant produit une telle quantité de pointes, qu'il s'agisse de la phase ancienne ou récente du Paléolithique moyen. Seules les productions levantines datant de la fin du Paléolithique moyen s'offrent comme point de comparaison technique, à l'instar du gisement de Kebara en Israël (Meignen, BarYosef, 1991; Meignen, 1995).

Concernant les «zones de combustion», des prélèvements ont été réalisés afin d'analyser la susceptibilité magnétique du sédiment. Dans la même optique, des prélèvements ont été effectués afin d'être soumis à un test ESR permettant de confirmer la chauffe du sable. Des blocs ont aussi été prélevés in situ afin de pouvoir mener une étude micromorphologique et physico-chimique qui permettront, entre autres, de déceler et de déterminer d'infimes fragments de charbons de bois ou de faune pouvant corroborer l'hypothèse de foyers en place. L'ensemble de ces investigations, couplées à une analyse fine de la répartition au sol des artefacts chauffés et des artefacts non soumis à l'action du feu, devrait permettre de mieux caractériser les «zones de combustion» (Hérisson, en cours).

Cette étude préliminaire, complétée par différentes études en cours de réalisation, vont permettre de mieux appréhender les comportements des Néandertaliens venus s'implanter au pied du mont de Bourguillemont il y a environ 180000 ans et de compléter nos connaissances sur une période encore peu documentée pour le Nord-Ouest de l'Europe: la phase ancienne du Paléolithique moyen. 


\title{
BIBLIOGRAPHIE
}

\author{
AbRÉviations \\ AEP Archives d'écologie préhistorique. \\ AFEQ Association française pour l'étude du Quaternaire. \\ APDCA Association pour la promotion et la diffusion des connaissances archéologiques. \\ BSPF Bulletin de la Société préhistorique française. \\ CERP Centre d'études et de recherches préhistoriques. \\ DAF Documents d'archéologie française. \\ MSH Maison des sciences de l'homme. \\ SPF Société préhistorique française.
}

\section{Abril J.-C., Clisson G., MARC D.}

1981: «La coupe de matériaux. Étude technologique de la coupe. Étude économique de la coupe. L'outil de la coupe", in Les Fabrications mécaniques, Paris, éd. Nathan (coll. Techniques industrielles), $288 \mathrm{p}$.

\section{ADAM A.}

1991: «Le gisement paléolithique moyen du Rissori à Masnuy-Saint-Jean (Hainaut, Belgique): premiers résultats", in Tuffreau A. (DIR.), Paléolithique et Mésolithique du nord de la France: nouvelles recherches, II, Université des sciences et techniques de Lille, CERP, p. 41-52.

AdAM A., TUfFreau A.

1973: «Le gisement paléolithique ancien du Rissori, à Masnuy-Saint-Jean (Hainaut, Belgique) », $B S P F, 70$, p. 293-310.

\section{ANTOINE $\mathbf{P}$.}

1990: Chronostratigraphie et environnement du Paléolithique du Bassin de la Somme, Université des sciences et techniques de Lille, CERP, 231 p.

2002: «Contexte stratigraphique et paléopédologique; interprétation chronostratigraphique et environnementale», in LOCHT J.-L. (DIR.), Le Site de BettencourtSaint-Ouen (Somme): cinq occupations $d u$ Paléolithique moyen au début de la dernière glaciation, Paris, éd. MSH (coll. DAF, 90), p. 16-39.

ANTOINe P., Bahain J.-J., DEBENHAM N., Frechen M., GaUthier A., HatTÉ C., LIMONDIN-LOZOUET N., LOCHT J-L., RAYMOND P., ROUSSEAU D.D.

2003: «Nouvelles données sur le Pléistocène du nord du Bassin parisien: les séquences lœssiques de Villiers-Adam (Val d'Oise, France)», Quaternaire, 14, p. 219-235.

Antoine P., LAUTRIdou J.-P., SOMme J., Auguste P., AUfFret J.-P., BAIZe S., CletPellerin M., Coutard J.-P., DeWOlF Y., DUGUE O., JOLY F., LAIGNEL B., LAURENT M., LAVOlle M., LEBReT P., LECOlle F., LEFEBVRE D., LIMONDIN-LOZOUET N., Munaut A.-V., OZOUF J.-C., QUESNEL F., ROUSSEAU D.-D.

1998: «Les formations quaternaires de la France du Nord-Ouest: limites et corrélations », Quaternaire, 9, 3, p. 227-241.

\section{Antoine P., Munaut A.-V., Somme J.}

1994: «Réponse des environnements à l'évolution climatique du Début Glaciaire weichsélien: données de la France du Nord-Ouest», Quaternaire, 5, p. 151-156.

\section{ANTOINe P., RousSEAU D.-D.} LAUTRIDOU J.-P., HATTÉ C.

1999: «Last Interglacial-Glacial climatic cycle in loess-palaeosol successions of northwestern France», Boreas, 28, p. 551-563.

Antoine P., Rousseau D.D., MoIne O., KUNESCH S., HATTÉ C., LANG A., TISSOUX H., ZÖLLER L.

2009: «Rapid and Cyclic Eolian Deposition during the Last Glacial in European Loess: a High-Resolution Records from Nussloch (Germany) », Quaternary Science Reviews, 28, p. 2955-2973.

ANTOINe P., RousseaU D.-D., ZOLler L., LANG A., MUNAUT A.-V., HatTÉ C., FONTUGNE M.

2001: «High resolution record of the last Interglacial-Glacial cycle in the Nussloch loess-palaeosol sequences, Upper Rhine
Area Germany ", Quaternary International, 76-77, p. 211-229.

\section{ASHTON N., JACOBI R., WHITE M.}

2003: «The dating of Levallois sites in West London", Quaternary Newsletter, 99, p. 25-32.

BOËDA É.

1982: «Étude expérimentale de la technologie des pointes Levallois» in CAHEN D. (DIR.), Tailler! Pour quoi faire: Préhistoire et technologie lithique -II-. Recent Progress in Microwear Studies, URA 28 et Studia Praehistorica Belgica Leuven, 2, p. 25-36.

1994: Le Concept Levallois: variabilité des méthodes, Paris, éd. du CNRS (coll. Monographies du CRA, 9), $280 \mathrm{p}$.

BOËDA É., BOURGUIGNON L., GROGGO C. 1998: "Activités de subsistance au Paléolithique moyen: couche V13 b' du gisement d'Umm el Tlel (Syrie)», in BRUgal J.-P., Meignen L., PatoUMATHIS M. (DIR.), Économie préhistorique: les comportements de subsistance au Paléolithique, Actes des XVIII rencontres internationales d'archéologie et d'histoire d'Antibes, 23-25 oct. 1997, SophiaAntipolis, APDCA, p. 243-258.

BORDES F.

1961: Typologie du Paléolithique ancien et moyen, Bordeaux, éd. Delmas, 101 p., 108 pl.

\section{CAHEN D., Michel J.}

1986: «Le site paléolithique moyen ancien de Mesvin IV (Hainaut, Belgique)», in Tuffreau A., SOMme J. (DIR.), Chronostratigraphie et faciès culturels $d u$ Paléolithique inférieur et moyen dans l'Europe $d u$ Nord-Ouest, Actes du $22^{e}$ congrès préhisto- 
rique de France, Lille, 4-6 sept. 1984, Paris (coll. Suppl. au bulletin de l'AFEQ, 26), p. 89-102.

\section{CAllow P.}

1986: «The saalian industries of La Cotte de Saint Brelade, Jersey", in TUFfREAU A., SOMME J. (DIR.), Chronostratigraphie et faciès culturels du Paléolithique inférieur et moyen dans l'Europe du Nord-Ouest, Actes du $22^{e}$ congrès préhistorique de France, Lille, 4-6 sept. 1984, Paris (coll. Suppl. au bulletin de l'AFEQ, 26), p. 129-140.

CAllow P., CORNFORD J.-M. (DIR.)

1986: La Cotte de Saint Brelade (Jersey) 19611978: excavations by C.B.M. Mc Burney, Norwich, Geobooks, 433 p.

CLIQUeT D. (DIR.)

2009: Le Site pléistocène moyen récent de Ranville (Calvados, France) dans son contexte environnemental: analyse du fonctionnement d'une aire de boucherie soutirée par un réseau karstique, Université de Liège (coll. ERAUL, 119), $210 \mathrm{p}$.

DElAGNeS A., ROPARS A. (DIR.)

1996: Paléolithique moyen en pays de Caux (HauteNormandie). Le Pucheuil, Ettouteville: deux gisements de plein air en milieu loessique, Paris, éd. MSH (coll. DAF, 56), 244 p.

\section{DE LOEGKER D.}

2004: Beyond the site: the Saalian archaeological record at Maastricht-Belvédère (The Netherlands), Leiden, éd. University of Leiden (coll. Analecta Prchistorica Leidensia, 21), $300 \mathrm{p}$.

\section{FISHER T. G.}

1996: «Sand wedges and ventifact palaeoenvironmental indicators in NorthWest Saskatchewan, Canada, 11 ka to 9.9 ka BP», Permafrost and Periglacial Processes, 7, p. 391-408.

\section{FRENCH H. M., GOZDZIK J.}

1988: «Pleistocene epigenetic and syngenetic frost fissures, Belchatow, Poland", Canadian Journal of Earth Sciences, 25, p. 2017-2027.

\section{GADEBOIS G.}

2006: Therdonne. Étude technologique et technique de la production de pointe Levallois et d'éclats Levallois triangulaires: un aspect comportemental des modalités de gestion lithique des Néandertaliens, Mémoire de Master 2, Université Lille-I, 151 p.
Green H. S., BeVins R. E., BUll P. A., Currant A. P., Debenham N. C., EMBLETON C., IVANOVICH M., LIVINGSTON H., RAE A. M., SCHWARCZ H. P., STRINGER C. B. 1989: «Le site acheuléen de la grotte de Pontnewydd, Pays de Galles: géomorphologie, stratigraphie, chronologie, faune, hominidés fossiles, géologie et industrie lithique dans le contexte paléoécologique », L'Anthropologie, 93, 1, p. 15-52.

\section{Guilbaud M., Carpentier G.}

1995: «Un remontage exceptionnel à Tourville-la-Rivière (Seine-Maritime) », $B S P F$, 92, 3, p. 289-295.

\section{GULLENTOPS F.}

1954: "Contribution à la chronologie du Pléistocène et des formes de relief en Belgique", Mémoires de l'Institut géologique de l'université de Louvain, XVIII, p. 125252.

\section{Heinzelin J. De, HAEsaerts P.}

1983: «Un cas de débitage laminaire au Paléolithique ancien: Croix-l'Abbé à Saint-Valéry-sur-Somme», Gallia Préhistoire, 26, 1, p. 189-201.

\section{HÉRISSON D.}

2007: Stratégie de réduction des nucléus du niveau 3 du gisement paléolithique moyen de Therdonne (Oise, France), Mémoire de Master 2, Université Lille-I, 148 p.

En cours: Étude des comportements des premiers Néandertaliens du nord de la France: les occupations saaliennes des gisements de Biache-Saint-Vaast et de Therdonne, Thèse de $3^{\mathrm{e}}$ cycle, Université Lille-I.

HÉRISSON D., Goval E., LEFEBVRE B.

À paraître: «Éléments de réflexion sur la place de la France septentrionale en Europe du Nord-Ouest durant la phase ancienne du Paléolithique moyen", in DePaepe P., Goval E., Koehler H., LOCHT J.-L. (DIR.), Les Plaines du NordOuest: carrefour de l'Europe au Paléolithique moyen ?, Actes des journées de la SPF, Amiens, 28-29 mars 2008, Paris, SPF (coll. Mémoires de la SPF).

\section{INIZAN M.-L., REDURON-BALLINGER M.,} ROCHE H., TIXIER J.

1995: Technologie de la pierre taillée, in Préhistoire de la pierre taillée, 4, Meudon, CREP, 199 p.

\section{JUNKMANNS J.}

1995: «Les ensembles lithiques d'Achenheim d'après la collection de Paul Wernert", $B S P F$, 92, 1, p. 26-36.

\section{LAURENT M.}

1993: Datation par résonance de spin électronique (ESR) de quartz de formations quaternaires: comparaison avec le paléomagnétisme, Thèse de $3^{\mathrm{e}}$ cycle, Museum national d'histoire naturelle, $103 \mathrm{p}$.

\section{LAUTRIDOU J.-P., SOMME J., HeIM J.,} PUISSEGUR J.-J., ROUSSEAU D.-D.

1985: «La stratigraphie des lœss et formations fluviatiles d'Achenheim (Alsace): nouvelles données bioclimatiques et corrélations avec les séquences pléistocènes de la France du Nord-Ouest ", Bulletin de l'AFEQ, 22-23, 2-3, p. 125-132.

\section{LEPOT M.}

1993: Approche technofonctionnelle de l'outillage lithique moustérien: essai de classification des parties actives en termes d'efficacité technique. Application à la couche M2e sagittale du grand abri de la Ferrassie, Mémoire de Maîtrise, Université Nanterre Paris-X, vol. I, 161 p., vol. II, 90 pl.

\section{LOCHT J.-L.}

2001: «Modalités d'implantation et fonctionnement interne des sites: l'apport de trois gisements de plein air de la phase récente du Paléolithique moyen dans le nord de la France (Bettencourt-SaintOuen, Villiers-Adam et Beauvais)", in Conard N. J. (DIR.), Settlement Dynamics of the Middle Paleolithic and Middle Stone Age, vol. I, Tübingen, Kerns Verlag, p. $361-393$.

2004: Le Gisement paléolithique moyen de Beauvais (Oise), Thèse de $3^{\mathrm{e}}$ cycle, Université Lille-I, vol. I: 209 p., vol. II: 127 pl.

\section{LOCHT J.-L. (DIR.)}

2002: Le Site de Bettencourt-Saint-Ouen (Somme), cinq occupations du Paléolithique moyen au début de la dernière glaciation, Paris, éd. MSH (coll. DAF, 90), 176 p.

LOCHT J.-L., ANTOINe P., BAHAin J.-J., DWRILA G., RAYMOND P., LIMONDIN Lozouet N., GaUthier A., Debenham N., Frechen M., RousSeaU D.-D., HatTÉ C., HAESAERTS P., METSDAGH $\mathrm{H}$.

2003: «Le gisement paléolithique moyen et les séquences pléistocènes de VilliersAdam (Val-d'Oise, France) : chronostratigraphie, environnement et implantations humaines ", Gallia Préhistoire, 45, p. 1-111.

LOCHT J.-L., BAHAIN J.-J., DRWILA G., RAYMOND P., ANTOINE P., CASPAR J.-P., 
Debenham N. GaUthier A., Krier V., LIMONDIN N.

1997: Le Gisement paléolithique moyen du PetitSaule et la séquence pléistocène du Chameson de Villiers-Adam (Val-d'Oise), Document final de synthèse, AFAN/SRA Île-deFrance/SDA Val-d'Oise, vol. 1: 176 p., vol. 2: $127 \mathrm{pl}$.

LOChT J.-L., GUeRlin O., ANTOINe P., DEBENHAM N.

2000: Therdonne, le mont de Bourguillemont, Document final de synthèse, AFAN/SRA Picardie, 65 p.

LOCHT J.-L., SWINNEN C., ANTOINE P., Auguste P., Patou-Mathis M., DEPAEPE P., FAlgueres C., LAURENT M., BAHAIN J.-J.

1995: «Le gisement paléolithique moyen de

Beauvais (Oise) », BSPF, 92, 2, p. 213-226.

MARTINSON D. G., Pisias N. G.,

HAYS J. D., IMBRies J., MOORE T. C., SHACKLETON N. J.

1987: «Age dating and the orbital theory of the Ice ages: development of a highresolution 0 to 300,000-year chronostratigraphy", Quaternary Research, 27, p. 1-29.

\section{MEIGNEN L.}

1995: «Levallois lithic production systems in the Middle Palaeolithic of the Near East: the case of the unidirectional method", in Dibble H. L., BAR-YoseF O. (DIR.), The Definition and Interpretation of Levallois Technology, Madison, ed. Prehistory Press (coll. Monographs in World Archaeology, 23), p. 361-379.

\section{MEIGNEN L., BAR-YOSEF O.}

1991: «Les outillages lithiques de Kebara (fouilles 1982-1985)", in BAR-YOSEF O., VANDERMEERSCH B. (DIR.), Le Squelette moustérien de Kebara, Paris, CNRS Éditions (coll. Cahiers de Paléoanthropologie), p. 49-76.

\section{MONNIER J.-L.}

1985: «Données nouvelles sur le gisement paléolithique moyen de Piégu (PléneufVal-André, Côtes-du-Nord)", Revue archéologique de l'Ouest, 2, p. 7-21.

Petit J.-R., JOUZEL J., RAYNAUd D., BARKOV N. I., BARNOLA J.-M., Basile I., Bender M., Chappellaz J., DAVIS M., Delaygue G., DelmotTe M., KOTLYAKOV V. M., LEGRAND M., LIPENKOV V. Y., LORIUS C., PÉPIN L., Ritz G., SAltzMan E., STIEVENARd M.

1999: «Climate and atmospheric history of the past 420,000 years from the Vostok ice core, Antarctica ", Nature, 399, p. 429436.

\section{ROEBROEKS W.}

1988: From Find Scatters to Early Hominids behaviour: a Study of Middle Palaeolithic Riverside Settlements at Maastricht-Belvédère (The Netherlands), Leiden, ed. University of Leiden (coll. Analecta Prehistorica Leidensia, 21), $196 \mathrm{p}$.

\section{SAINTy J., Thévenin A.}

1978: «Le sol 74», Recherches géographiques à Strasbourg, 7, p. 123-137.

\section{SCOTT B.}

2006: The Early Middle Palaeolithic of Britain: Origins, Technology and Landscape, Thèse, University of Durham, 351 p.

\section{SIEGEL P.}

1985: «Edge angle as a functional indicator: a test", Lithic Technology, 14, 2, p. 90-94.

\section{SORESSI M., LOCHT J.-L.}

2008: «L'outillage sur éclat: typologie, supports et potentiel fonctionnel ", in LOCHT J.-L. (DIR.), Le Petit Jardin à Angé
(Loir-et-Cher): un site paléolithique moyen à la confluence de toutes les influences, RFO/ SRA Centre, p. 143-190.

\section{SORIANO S.}

2000: Outillage bifacial et outillage sur éclat au Paléolithique ancien et moyen: coexistence et interaction, Thèse de $3^{\mathrm{e}}$ cycle, Université Nanterre Paris-X, 459 p.

THIEME H., BRUNNACKER K., JUVIGNE E.

1981: «Petrographische und argeschichtliche Untersuchungen in Lossprofil von Rheindahlen/Niederrheirische Bucht", Quartär, 31-32, p. 41-67.

\section{TUFFREAU A.}

1983: «Les industries à débitage laminaire du Paléolithique moyen de la France septentrionale», Studia Praehistorica Belgica, 3, p. 135-141.

\section{TUfFreaU A., BOUCheT P.}

1985: «Le gisement acheuléen de la vallée du Muid à Gouzeaucourt (Nord) », BSPF, 82, p. 291-306.

TUFFreau A., SOMmÉ J. (DIR.)

1989: Le Gisement paléolithique moyen de BiacheSaint-Vaast (Pas-de-Calais), Paris (coll. Mémoires de la SPF, 21), vol. 1, 340 p.

TURNer E., Boenick W., FreChEN M., VAN KOLFSCHOTEN T., SCHNEPP E., Sefkov E., STEensma A.

1997: «Ariendorf: Quaternary deposits and Palaeolithic excavations in the Karl Schneider gravel pit», Jahrbuch des römisch-germanischen Zentralmuseums Mainz, 44, p. 3-191.

\section{WILMSEM E. N.}

1968: «Functional analysis of flaked stone artefacts », American Antiquity, 33, p. 156161. 